\title{
Research on Evolutionary Game of Collaborative Innovation in Supply Chain under Digitization Background
}

\author{
Meili Lu $\left(\mathbb{D},{ }^{1}\right.$ Yujia Gao, ${ }^{1}$ and Qin Wan $\mathbb{D}^{2}$ \\ ${ }^{1}$ Business Administration College, Shanxi University of Finance and Economics, Taiyuan 030006, China \\ ${ }^{2}$ School of Economics and Management, Southwest Petroleum University, Chengdu 610500, China \\ Correspondence should be addressed to Qin Wan; wanqin1014@126.com
}

Received 2 July 2021; Accepted 6 November 2021; Published 24 November 2021

Academic Editor: Snežana Tadić

Copyright $\left({ }_{0} 2021\right.$ Meili Lu et al. This is an open access article distributed under the Creative Commons Attribution License, which permits unrestricted use, distribution, and reproduction in any medium, provided the original work is properly cited.

The development of digital technology has been rapidly pushing forward collaborative innovation in supply chain. This paper analyzes the influence mechanism of information sharing, resource integration, and trustworthiness among the enterprises in supply chain to collaborative innovation under the digitization background and builds the model of dynamic evolutionary game in which enterprises in supply chain participate collaborative innovation, and then, through the methods of model solution analysis and numerical simulation the following concrete conclusions are reached: the increase of data sharing profit coefficient, resource integration coefficient, and trustworthiness causes the increase of the probability that an enterprise selects to participate collaborative innovation in supply chain, and the increase of data sharing cost, security risk coefficient, and free rider income causes the decrease of the probability that an enterprise selects to participate collaborative innovation in supply chain; meanwhile, the increase of all the coefficients makes the velocity with which decision-making approaches to the direction toward decision higher and higher, and when the core enterprises participate the game, they can drive the common enterprises make decision more rapidly; and for the probability that an enterprise selects to participate collaborative innovation in supply chain, data sharing profit coefficient, data sharing cost coefficient, security risk coefficient, and free rider income have threshold values. These conclusions play active roles in leading enterprises to attach importance to digitization construction and actively participate collaborative innovation in supply chain.

\section{Introduction}

In the wake of disseminating and applying the digital technologies of big data, cloud computing, and artificial intelligence, the modern society has been entering the digitization era [1]. The digital technology changed the basic form of existing products, the mode of new products' manufacturing procedure, and the business model and organization form, what is more, overturned the basic hypotheses of many innovation theories [2]. The digitization innovation of supply chain management has become an important way for enterprises improving competitive advantage [3].

More and more enterprises have recognized the significance of collaborative innovation in supply chain under the digitization background. For instance, by using of technology energization, JD launched the Kepler project to promote data sharing and improve the collaborative ability among the cooperative partners. Through the supply chain system driven by data, Handu Group integrated resources of many small enterprises and with group system realized the high-level collaboration and cooperation. By means of various integrative digital technologies, Tader Coal built a sharing system for the coal supply chain service so as to enhance mutual trust and promote coal trade. With the help of digital technology, all of these enterprises realized the successful transition and collaboration innovation of enterprises by means of information sharing, resource integration, and enhancing trustworthiness. Also, there are a number of famous successful enterprises such as Boeing, Ford, Huawei, and Haier that hold overwhelming leads in the innovation field by reason of the active practice of 
collaboration innovation together with both upstream and downstream enterprises $[4,5]$.

Scholars have done much research on supply chain collaboration, but there are not many literature works on supply chain collaboration innovation. Since 1990s, scholars and practitioners have been energetically pushing forward collaboration under the background of supply chain [6] and exploring the subjects of the concept of collaboration on supply chain [7-9], the concrete action of collaboration [10], influence factors of collaboration $[11,12]$, the game between upstream and downstream in the process of collaboration [13], and so on. Because the collaboration innovation is driven by the developments of the integration of industry and technology [14], the demand of wide-ranging stakeholder's making value, attraction for new market and consumer group, and response to new business model, scholars began new exploration around collaboration innovation in supply chain [15]. At present, scholars have relatively studied the relationship between data sharing and supply chain collaborative innovation, but few in resource integration and trust. The development in information technology has promoted the communication and real-time sharing of information among the members of supply chain [16], data sharing can significantly influence the performance of supply chain, and sharing future order information with the supplier is more beneficial than sharing only the future demand information, thus the cooperative partners in supply chain share the information of prediction and production plan, and the well coordination of business activities among enterprises is realized [17]; therefore, the collaboration innovation promotes the improvement of enterprises' performance in many aspects $[18,19]$. In recent years, the scholars have been carrying on the research centered on the collaboration in the pull supply chain [20], the collaboration in supply chain in the big data era [21], the collaboration in supply chain under the new retail background [9], and so on. As the innovation process itself could be influenced by digitization, scholars hold that the accepted innovation theories are no longer suitable in use $[2,22,23]$ and under the background of digitization it is necessary to find a new innovation theory. There are some scholars who study the supply chain by the game theory. The relationships between sellers and buyers have been modeled by non-cooperative and cooperative games [24]. Evolutionary dynamics has been adopted extensively to locate the optimal and the most stable point offering the best economic gains in the analysis of green supply chain contracts between the producer and the retailer [25]. There is a study that investigates the games between governments and core enterprises in greening supply chains, and this article analyzes their respective costs and benefits and studies the evolutionary game model. Game analysis shows that core enterprises' costs and benefits to implement green supply chain management as well as subsidies and penalties from governments directly affect the game results [26]. However, the evolutionary game method has not been used in the collaborative innovation of supply chain, and it has not been studied in combination with the current digital background.
Combining with the background of digitization era, this paper researches the effects of information sharing, resource integration, and trustworthiness by digital empowerment on collaboration innovation in supply chain. In consideration of the characteristics of the complexity and dynamics in supply chain, the method of evolutionary game is applied to research the question of system innovation in supply chain. In the part of numerical simulation, when verifying respectively the effect of the coefficients such as data sharing profit coefficient, resource integration, and trustworthiness, we considered whether the core enterprises' participation can produce different results of collaboration innovation.

The structure arrangement of this paper is as follows: the first part is introduction; the second part is to analyze the mechanism of collaboration innovation in supply chain under the digitization background; the third part puts forward the basic hypotheses and a evolutionary game theory model; the fourth part is to analyze the model's strategic stability; then, we start numerical simulation to verify the statements; and last, we write the research conclusion and enlightenment.

\section{Analysis of the Effect Mechanism of Collaboration Innovation in Supply Chain under the Digitization Background}

Whether the two companies in the supply chain collaborate to innovate is a game process. We take a total Internet group of supply chain as a natural system, which is divided into two subgroups randomly, and from each subgroup, we select randomly an enterprise to make them pair up with each other for playing the game several times. Each side of the game selects the decision to participate collaboration innovation or selects the decision not to participate collaboration innovation in supply chain. Based on the hypothesis of bounded rational man, both sides always search for the optimum strategy on the balance of income and cost.

The collaboration innovation of enterprises pursues full information sharing, mutual trustworthiness, and the realization of benefit claim [27]. Firstly, collaboration innovation in supply chain is based on information sharing. Information sharing refers to the sharing of private information owned by each participant in the supply chain. Information sharing energizes enterprises to carry on collaboration innovation in the three aspects of data sharing, technology sharing, and knowledge sharing [28]. The sharing of data, resource, and technology has great influence on the realization of product innovation by collaboration in supply chain [29]. Information sharing cannot be carried out without the support of data resource since data technology causes the progressive and disruptive innovation for collaboration in supply chain [30], and data sharing is the key factor in the realization of collaboration in supply chain, which can improve the performance of collaboration innovation in supply chain [31]. The knowledge sharing is processed in a deep level on the basis of data and technology and shapes into the sharing form for direct use easily, so as to energize enterprises with high efficiency for realization of 
collaboration innovation [32]. The income quantity depends on the ability of turning information into income and the quantity of shared information, i.e., the greater the quantity of shared information, the more beneficial to enterprises obtaining more comprehensive information and improving the acuity of supply chain [33], and then improving the income of supply chain. The two-way information flow is of benefit to the improvement of the performance in collaboration innovation [34]. In the context of digitalization, the most obvious manifestation is that data expand the information sharing from all aspects than that develop in the information age, so data sharing is more suitable for the current development environment than information sharing. Therefore, the income coefficient of data sharing can be introduced to express an enterprise's ability of turning data into income. Meanwhile, data sharing needs to pay cost, so the cost has become an important factor in restricting the data sharing among enterprises. The core enterprises play leading and overall planning roles that make supply chain run with high efficiency, so that the channel cost and time cost produced in the process of data sharing can be reduced [35]. Besides, data leakage in the process of data sharing caused by the poor work of information protection makes the collaborative side take the security risk of being imitated and copied and then makes the income of innovation decreased [34], and therefore, it is necessary to analyze the influence of security risk during collaborative innovation in supply chain.

Secondly, collaboration innovation in supply chain always manifests itself as a process of resource integration. Resource integration is mainly to integrate the resources owned by each participant in the supply chain in order to achieve high efficiency. Resource integration can produce the resource beaming effect, that is, the efficiency of using a large number of resources integrated is higher than the efficiency of using a kind of resource alone [36]. For the similar resources, the scale economy is applied for reducing cost and increasing income; for the complementary resources, the scope economy is applied for raising collaboration income as well as giving full play to the resource collaboration effect [37], briefly, both of them can likewise lead to success [38]. The digital resource collaboration among enterprises is of benefit to the integration of all existing logistics resources and customer resources of cooperation partners in the supply chain [39], who improve the efficiency of supply chain through standardization construction, centralized purchase, and supplier management $[40,41]$, as well as gain continuous income through the integration of the relationship between suppliers and customers [42]. The ability of resource integration is indicated with resource integration coefficient, so it can be found that the bigger the coefficient is, the higher the collaborative innovation income gains, and when the core enterprises exist, their resource integration ability is stronger than that of common enterprises.

Finally, as a main factor [43] that restricts cooperation intensity, trustworthiness is the core of cooperation innovation ability [44]. The higher is the degree of reciprocity and the stronger is the relationship among partners in the supply chain, the higher is the mutual trustworthiness. Digitization improves the degree of open and transparence of information and relieves the pressure of information asymmetry, as a result, enterprises obtain more smooth communication than before through explaining energization [45]. It is important to communicate in time for resolution of disputes and reach an identical opinion, and it is beneficial to the common strategy decision and collaborative innovation among enterprises, also, in the aspect of enterprise cost input, the improvement is achieved [46]. The direct and efficient communication can enhance the exchange efficiency [47], and the produced trustworthiness can increase the collaborative innovation performance [46]. Among enterprises, the higher is the trustworthiness, the higher is the desire for sharing information; what is more, in order to overcome the obstacle of information communication system, enterprises may invest again to reform their inner information system [48].

\section{Basic Hypothesis and Modeling}

\subsection{Basic Hypothesis}

Hypothesis 1. In a certain supply chain, we take an enterprise as a natural system and divide it into group 1 and group 2. Each group has several enterprises and all of them are bounded rationality. Every enterprise can have two decisions, i.e., selecting to participate or not to participate collaboration innovation in supply chain, so the strategy set of enterprise is \{to participate collaboration innovation in supply chain (be simplified as "participation strategy"), not to participate collaboration innovation in supply chain (be simplified as "no participation strategy")\}. In the game process, if an enterprise in this round game do not find that the profit of those enterprises participated collaboration innovation in supply chain is lower than the profit of those enterprises not participated collaboration innovation in supply chain, this enterprise will select to participate collaboration innovation in supply chain in the next round of game; in reverse, if the profit of an enterprise who did not participate collaboration innovation in supply chain is higher than the profit of those enterprises participated collaboration innovation in supply chain, still, this enterprise will not select to participate collaboration innovation in supply chain.

Hypothesis 2: When the two enterprises select "participation strategy," the collaboration effect first arises and the basis income $R_{1}^{i}(i=A, B)$ is obtained, which is greater than the communication collaboration cost among enterprises. After that, because product innovation and business model innovation bring the enterprises the collaboration innovation income and in the process of collaboration innovation there are influence of the factors of information sharing, trustworthiness, and resource integration, the information quantity $P_{i}(i=A, B)$, the data sharing profit coefficient $\alpha_{i}(i=A, B)$, the data sharing cost coefficient $\beta_{i}(i=A, B)$, and the security risk coefficient $\gamma_{i}(i=$ 
$A, B)$ are introduced. In the aspect of trustworthiness, the trustworthiness coefficient $\varepsilon_{A B}$ is introduced, and we assume that when enterprises totally distrust each other the communication collaboration cost, which should be paid is $C_{0}$, obviously, the more is $\varepsilon_{A B}$, the more is the decrease in the amplitude of collaboration cost, and therefore, $1-\varepsilon_{A B}$ can indicate the decrease proportion of communication cost. In the influence of resource integration, the resource integration ability coefficient $\delta_{i}(i=A, B)$ and extra income $R_{2}^{i}(i=A, B)$ of resource integration are introduced, and we assume that in the process of resource integration the cost of input in the platform or standardization construction is $C_{1}^{i}(i=A, B)$.

Hypothesis 3: In the game, when one side of enterprises selects the "participation strategy" and the other one selects the "no participation strategy," as for the enterprises not participated, the free rider behavior is inevitable, so we assume that the income from free rider is $R_{3}^{i}(i=A, B)$. Because the two sides do not reach cooperation, the side that selected to participate cannot obtain collaborative innovation income; in the meantime, we assume that when the two enterprises do not reach cooperation, the equally shared collaboration cost is $C_{0}$, that is, the collaboration cost of each enterprise is $(1 / 2) C_{0}\left(R_{3}^{i}>(1 / 2) C_{0}\right)$.

Hypothesis 4: When the two enterprises select the "no participation strategy," each side of them just obtains existing income $R_{0}^{i}(i=A, B)$.

Hypothesis 5: The probabilities that the two enterprises $A$ and $B$ select to participate collaborative innovation in supply chain are $x$ and $y$, and the probabilities that the two enterprises select not to participate collaborative innovation in supply chain are $1-x$ and $1-y$, and $x, y \in[0,1]$; all of them are the function of time $t$.

3.2. Evolutionary Game Modeling. According to the strategy selection, the income matrix of 4 kinds of selections is listed in Table 1.

According to the game payoff matrix and evolutionary game theory, when the enterprise $A$ selects the "participation strategy," its income is

$$
E_{A 1}=y\left(R_{0}^{A}+R_{1}^{A}-\frac{1}{2}\left(1-\varepsilon_{A B}\right) C_{0}+\delta_{A}\left(R_{2}^{A}-C_{1}^{A}\right)+\left(\alpha_{A}-\beta_{A}-\gamma_{A}\right) P_{A}\right)+(1-y)\left(R_{0}^{A}-\frac{1}{2} C_{0}\right)
$$

When the enterprise A selects the "no participation strategy," its income is

$$
E_{A 2}=y\left(R_{0}^{A}+R_{3}^{A}-\frac{1}{2} C_{0}\right)+(1-y) R_{A} .
$$

So, the average income of enterprise $A$ is

$$
\overline{E_{A}}=x E_{A 1}+(1-x) E_{A 2}
$$

When the enterprise $B$ selects the "participation strategy," its income is

$$
E_{B 1}=x\left(R_{0}^{B}+R_{1}^{B}-\frac{1}{2}\left(1-\varepsilon_{A B}\right) C_{0}+\delta_{B}\left(R_{2}^{B}-C_{1}^{B}\right)+\left(\alpha_{B}-\beta_{B}-\gamma_{B}\right) P_{B}\right)+(1-x)\left(R_{0}^{B}-\frac{1}{2} C_{0}\right)
$$

When the enterprise $B$ selects the "no participation strategy," its income is

$$
E_{B 2}=x\left(R_{0}^{B}+R_{3}^{B}-\frac{1}{2} C_{0}\right)+(1-x) R_{B}
$$

So, the average income of enterprise $B$ is

$$
\overline{E_{B}}=y E_{B 1}+(1-y) E_{B 2} \text {. }
$$

We solve the replicated dynamic equation: 
TABLE 1: Payoff matrix for both sides of the game.

\begin{tabular}{cccc}
\hline \multicolumn{1}{c}{ Income } & & $B$ \\
& & Participation $(y)$ & No participation $(1-y)$ \\
\hline \multirow{2}{*}{ Aarticipation $(x)$} & $A: R_{0}^{A}+R_{1}^{A}-\frac{1}{2}\left(1-\varepsilon_{A B}\right) C_{0}+\delta_{A}\left(R_{2}^{A}-C_{1}^{A}\right)+\left(\alpha_{A}-\beta_{A}-\gamma_{A}\right) P_{A}$ & $A: R_{0}^{A}-(1 / 2) C_{0}$ \\
& $B: R_{0}^{B}+R_{1}^{B}-\frac{1}{2}\left(1-\varepsilon_{A B}\right) C_{0}+\delta_{B}\left(R_{2}^{B}-C_{1}^{B}\right)+\left(\alpha_{B}-\beta_{B}-\gamma_{B}\right) P_{B}$ & $B: R_{0}^{B}+R_{3}^{B}-(1 / 2) C_{0}$ \\
& & $A: R_{0}^{A}+R_{3}^{A}-(1 / 2) C_{0}$ & $A: R_{0}^{A}$ \\
& & $B: R_{0}^{B}-(1 / 2) C_{0}$ & $B: R_{0}^{B}$ \\
\hline
\end{tabular}

$$
\begin{aligned}
& F(x)=\frac{\mathrm{d} x}{\mathrm{~d} t}=x\left(E_{A 1}-\overline{E_{A}}\right)= \\
& x(1-x)\left[y\left(R_{1}^{A}-\frac{1}{2}\left(1-\varepsilon_{A B}\right) C_{0}+\delta_{A}\left(R_{2}^{A}-C_{1}^{A}\right)+\left(\alpha_{A}-\beta_{A}-\gamma_{A}\right) P_{A}-R_{3}^{A}+C_{0}\right)-\frac{1}{2} C_{0}\right], \\
& F(y)=\frac{\mathrm{d} y}{\mathrm{~d} t}=y\left(E_{B 1}-\overline{E_{B}}\right)= \\
& y(1-y)\left[x\left(R_{1}^{B}-\frac{1}{2}\left(1-\varepsilon_{A B}\right) C_{0}+\delta_{B}\left(R_{2}^{B}-C_{1}^{B}\right)+\left(\alpha_{B}-\beta_{B}-\gamma_{B}\right) P_{B}-R_{3}^{B}+C_{0}\right)-\frac{1}{2} C_{0}\right] .
\end{aligned}
$$

\section{Analysis of Evolutionary Game Model}

4.1. Analysis of Strategic Stability of the Enterprise A. When $F\left(x^{*}\right)=(\mathrm{d} x / \mathrm{d} t)=0, x^{*}$ is the stable point of this replicated dynamic equation. And when $F\left(x^{*}\right)=0$ and
$F^{\prime}\left(x^{*}\right)<0, x^{*}$ is the stability strategy of this evolutionary game.

From $F(x)=0$, we get

$$
\begin{aligned}
& x^{*}=0, \\
& x^{*}=1, \\
& y^{*}=\frac{(1 / 2) C_{0}}{R_{1}^{A}-(1 / 2)\left(1-\varepsilon_{A B}\right) C_{0}+\delta_{A}\left(R_{2}^{A}-C_{1}^{A}\right)+\left(\alpha_{A}-\beta_{A}-\gamma_{A}\right) P_{A}-R_{3}^{A}+C_{0}}=\frac{C_{0}}{2 \rho_{1}} .
\end{aligned}
$$

Here,

$$
\rho_{1}=R_{1}^{A}-\frac{1}{2}\left(1-\varepsilon_{A B}\right) C_{0}+\delta_{A}\left(R_{2}^{A}-C_{1}^{A}\right)+\left(\alpha_{A}-\beta_{A}-\gamma_{A}\right) P_{A}-R_{3}^{A}+C_{0}
$$

Analyzing $F^{\prime}(x)=(1-2 x)\left[\rho_{1} y-(1 / 2) C_{0}\right]$, we get the following conclusions:

(1) When $\rho_{1}<(1 / 2) C_{0}, F^{\prime}\left(x^{*}=0\right)<0$; therefore, $x^{*}=0$ is the stability strategy of enterprise $A$, i.e., the enterprise $A$ is inclined not to participate innovation in supply chain. The phase graph is shown in Figure 1.

(2) When $\rho_{1}>(1 / 2) C_{0}, y<y^{*}$, then $F^{\prime}\left(x^{*}=0\right)<0$; therefore, $x^{*}=0$ is the evolutionary stability strategy of enterprise A. When $y>y^{*}$, then $F^{\prime}\left(x^{*}=1\right)<0$; therefore, $x^{*}=1$ is the evolutionary stability strategy of enterprise $A$, i.e., the enterprise $A$ selects to participate innovation in supply chain. The phase graph is shown in Figure 2.

4.2. Analysis of Strategic Stability of the Enterprise $B$. From $F(y)=0$, we get 

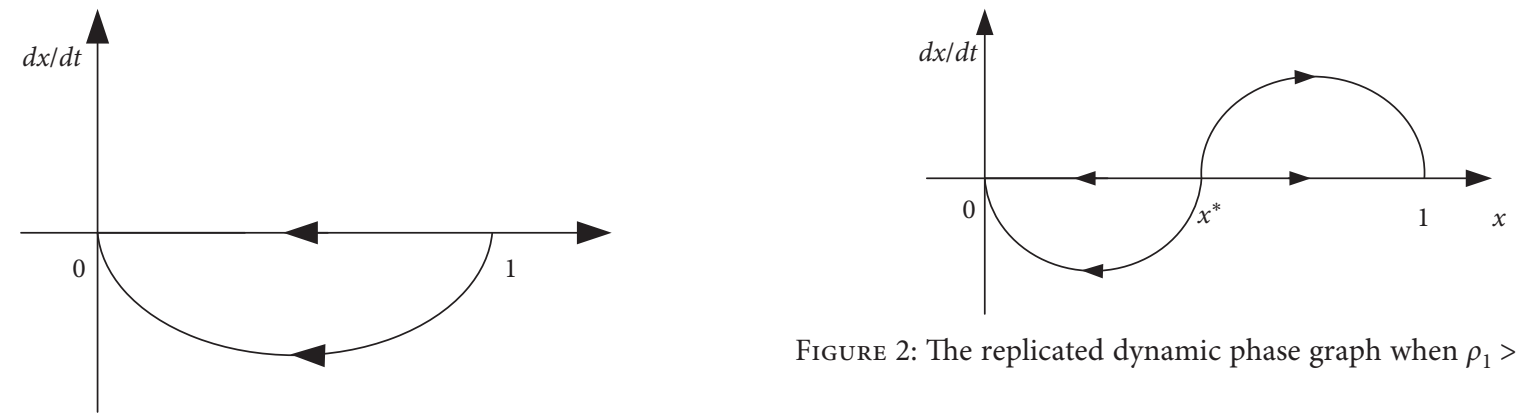

Figure 2: The replicated dynamic phase graph when $\rho_{1}>(1 / 2) C_{0}$.

FIgURE 1: The replicated dynamic phase graph when $\rho_{1}<(1 / 2) C_{0}$.

$$
\begin{aligned}
& y^{*}=0, \\
& y^{*}=1, \\
& x^{*}=\frac{(1 / 2) C_{0}}{R_{1}^{B}-(1 / 2)\left(1-\varepsilon_{A B}\right) C_{0}+\delta_{B}\left(R_{2}^{B}-C_{1}^{B}\right)+\left(\alpha_{B}-\beta_{B}-\gamma_{B}\right) P_{B}-R_{3}^{B}+C_{0}}=\frac{C_{0}}{2 \rho_{2}} .
\end{aligned}
$$

Here,

$$
\rho_{2}=R_{1}^{B}-\frac{1}{2}\left(1-\varepsilon_{A B}\right) C_{0}+\delta_{B}\left(R_{2}^{B}-C_{1}^{B}\right)+\left(\alpha_{B}-\beta_{B}-\gamma_{B}\right) P_{B}-R_{3}^{B}+C_{0}
$$

Analyzing $F^{\prime}(y)=(1-2 y)\left[\rho_{2} x-(1 / 2) C_{0}\right]$, we get the following conclusions:

(1) When $\rho_{2}<(1 / 2) C_{0}, F^{\prime}\left(y^{*}=0\right)<0$; therefore, $y^{*}=0$ is the evolutionary stability strategy of enterprise $B$, i.e., the enterprise $B$ is inclined not to participate innovation in supply chain. The phase graph is shown in Figure 3.

(2) When $\rho_{2}>(1 / 2) C_{0}, x<x^{*}$, then $F^{\prime}\left(y^{*}=0\right)<0$; therefore, $y^{*}=0$ is the evolutionary stability strategy of enterprise $B$. When $x>x^{*}$, then $F^{\prime}\left(y^{*}=1\right)<0$; therefore, $y^{*}=1$ is the evolutionary stability strategy of enterprise B, i.e., the enterprise B selects to participate innovation in supply chain. The phase graph is shown in Figure 4.
4.3. Analysis of Strategic Stability of Both Sides of Game. Combining $F(x)$ and $F(y)$, compose a dynamic system in which both sides of the enterprise $A$ and the enterprise $B$ play game, i.e., formula (12).

$$
\left\{\begin{array}{c}
F(x)=\frac{\mathrm{d} x}{\mathrm{~d} t}=x\left(E_{A 1}-\overline{E_{a A}}\right)=x(1-x)\left[\rho_{1} y-\frac{1}{2} C_{0}\right] \\
F(y)=\frac{\mathrm{d} y}{\mathrm{~d} t}=y\left(E_{B 1}-\overline{E_{B}}\right)=y(1-y)\left[\rho_{2} x-\frac{1}{2} C_{0}\right]
\end{array}\right\} .
$$

Set $F(x)=0, F(y)=0$, we find equilibrium points $A(0,1), C(1,0), B(1,1), G\left(x^{*}, y^{*}\right)$, in which

$$
\begin{aligned}
& x^{*}=\frac{(1 / 2) C_{0}}{R_{1}^{B}-(1 / 2)\left(1-\varepsilon_{A B}\right) C_{0}+\delta_{B}\left(R_{2}^{B}-C_{1}^{B}\right)+\left(\alpha_{B}-\beta_{B}-\gamma_{B}\right) P_{B}-R_{3}^{B}+C_{0}}=\frac{C_{0}}{2 \rho_{2}}, \\
& y^{*}=\frac{(1 / 2) C_{0}}{R_{1}^{A}-(1 / 2)\left(1-\varepsilon_{A B}\right) C_{0}+\delta_{A}\left(R_{2}^{A}-C_{1}^{A}\right)+\left(\alpha_{A}-\beta_{A}-\gamma_{A}\right) P_{A}-R_{3}^{A}+C_{0}}=\frac{C_{0}}{2 \rho_{1}} .
\end{aligned}
$$

The Jacobian matrix of this system is 


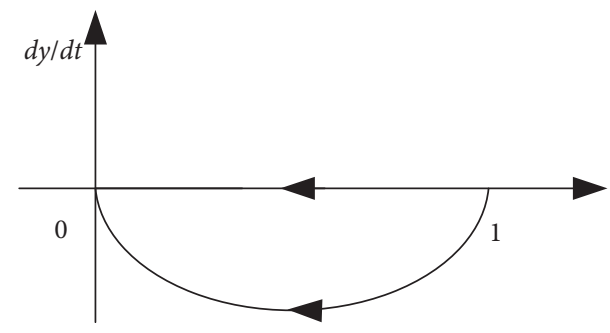

FIgURE 3: The replicated dynamic phase graph when $\rho_{2}<(1 / 2) C_{0}$.

$$
J=\left(\begin{array}{cc}
(1-2 x)\left[y \rho_{1}-\frac{1}{2} C_{0}\right] & x(1-x) \rho_{1} \\
y(1-y) \rho_{2} & (1-2 y)\left[x \rho_{2}-\frac{1}{2} C_{0}\right]
\end{array}\right)
$$

The determinant of Jacobian matrix is

$$
\begin{aligned}
\text { Det } J= & (1-2 x)\left[\rho_{1} y-\frac{1}{2} C_{0}\right](1-2 y)\left[\rho_{2} x-\frac{1}{2} C_{0}\right] \\
& -x(1-x) y(1-y) \rho_{1} \rho_{2} .
\end{aligned}
$$

The trace of Jacobian matrix is

$$
\operatorname{Tr} J=(1-2 x)\left(\rho_{1} y-\frac{1}{2} C_{0}\right)+(1-2 y)\left(\rho_{2} x-\frac{1}{2} C_{0}\right) \text {. }
$$

The collaborative innovation income obtained when both enterprises select the "participation strategy" is greater than that obtained when only one enterprise participates, and the income from free rider can be calculated with the expression about $\rho_{1}$ (9) and the expression about $\rho_{2}(11)$, $\rho_{1}>0, \rho_{2}>0$; therefore, the correlation properties of these five equilibrium points can be calculated with expression (15) and expression (16), i.e., the trace of Jacobian matrix, the sign of determinant, and the stability of results are shown in Table 2.

Table 2 shows that among the five equilibrium points, point $O(0,0)$ and point $C(1,1)$ satisfy the condition of Det $J>0, \operatorname{Tr} J<0$. They are evolutionary stable points and correspond, respectively, to the evolutionary game strategy \{not to participate collaborative innovation in supply chain, not to participate collaborative innovation in supply chain and to participate collaborative innovation in supply chain, to participate collaborative innovation in supply chain\}.

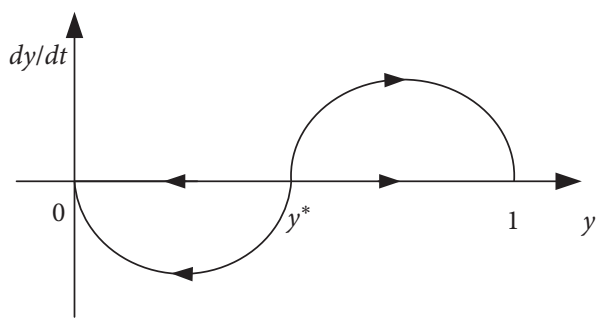

FIgURE 4: The replicated dynamic phase graph when $\rho_{2}>(1 / 2) C_{0}$.

TABle 2: Analysis of stability of local equilibrium points.

\begin{tabular}{lccc}
\hline Equilibrium points & Det $J^{\prime}$ s Sign & $\operatorname{Tr} J^{\prime} s$ Sign & Result \\
\hline$O(0,0)$ & + & - & ESS \\
$A(0,1)$ & + & + & Instability \\
$B(1,0)$ & + & + & Instability \\
$C(1,1)$ & + & - & ESS \\
$G\left(x^{*}, y^{*}\right)$ & - & 0 & Saddle point \\
\hline
\end{tabular}

Point $A(0,1)$ and point $B(1,0)$ are unstable points, $G\left(x^{*}, y^{*}\right)$ is the critical point, namely the saddle point, and the polygonal line of the three points converge to the evolutionary stable points $O(0,0)$ and $C(1,1)$. Based on the analysis of the stability of evolutionary game, the evolution phase graph of the enterprises in supply chain participating collaborative innovation in supply chain is drawn, which delineates the dynamic evolutionary process, as shown in Figure 5. As for the enterprises in supply chain, whether to select to participate collaborative innovation in supply chain chiefly is dependent upon the comparison between the total gained income and paid cost; therefore, the income and payoff matrix concerning enterprises participating collaborative innovation in supply chain and variation of every coefficient will influence the selection of strategy and finally converge to the corresponding equilibrium point.

The selection of strategy by both sides of game correlates with the area of quadrangle AOBG and quadrangle ACBG. The quadrangle AOBG indicates the probability that both sides select "no participation strategy." The quadrangle AOBG indicates the probability that both sides select "participation strategy," and the sum of the two parties is 1 . Let $S$ indicate the area of quadrangle AOBG, and expression (17) shows $S$. To analyze the factors that influence the variation of area, the evolutionary direction of system can be inferred.

$$
\begin{aligned}
& S=S_{O G B}+S_{O G A}=\frac{1}{2}\left(x^{*}+y^{*}\right)=\frac{1}{2}\left(\frac{C_{0}}{2 \rho_{2}}+\frac{C_{0}}{2 \rho_{1}}\right)=\frac{1}{4}\left(\frac{C_{0}}{\rho_{2}}+\frac{C_{0}}{\rho_{1}}\right)= \\
& \frac{1}{4}\left(\frac{C_{0}}{R_{1}^{B}-(1 / 2)\left(1-\varepsilon_{A B}\right) C_{0}+\delta_{B}\left(R_{2}^{B}-C_{1}^{B}\right)+\left(\alpha_{B}-\beta_{B}-\gamma_{B}\right) P_{B}-R_{3}^{B}+C_{0}}+\frac{C_{0}}{R_{1}^{A}-(1 / 2)\left(1-\varepsilon_{A B}\right) C_{0}+\delta_{A}\left(R_{2}^{A}-C_{1}^{A}\right)+\left(\alpha_{A}-\beta_{A}-\gamma_{A}\right) P_{A}-R_{3}^{A}+C_{0}}\right) .
\end{aligned}
$$




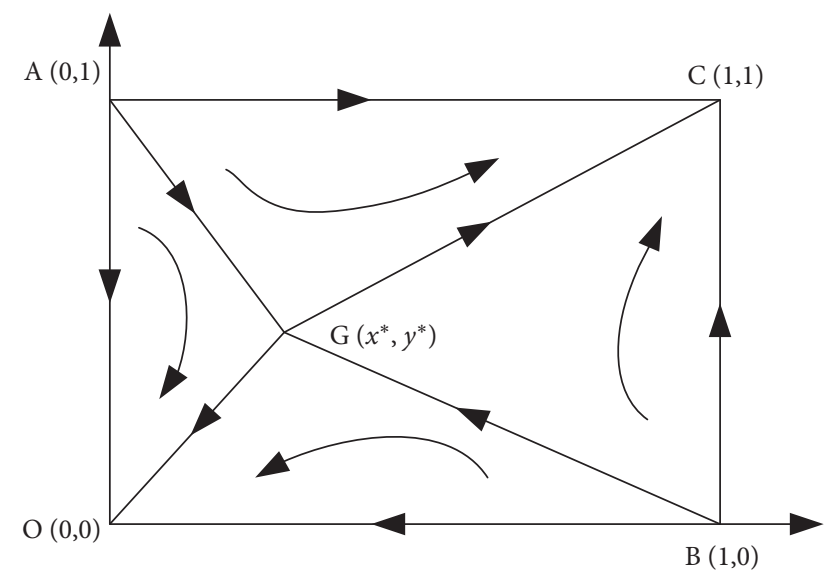

Figure 5: Phase graph of evolutionary game of enterprises participating collaborative innovation in supply chain.

Statement 1. The increase of data sharing profit coefficient improves the probability of an enterprise selecting to participate collaborative innovation in supply chain, and the velocity of approaching to the decision direction becomes higher and higher.

Proof. According to $\left(\partial S / \partial \alpha_{A}\right)=\left(-P_{1} C_{0} / 4\left(R_{1}^{A}-(1 / 2)(1-\right.\right.$ $\left.\left.\left.\varepsilon_{A B}\right) C_{0}+\delta_{A}\left(R_{2}^{A}-C_{1}^{A}\right)+\left(\alpha_{A}-\beta_{A}-\gamma_{A}\right) P_{A}-R_{3}^{A}+C_{0}\right)^{2}\right)$ $<0$, similarly, $\left(\partial S / \partial \alpha_{B}\right)<0$, it will be found that related to $\alpha_{i}$, $S$ appears monotone progressive decrease. It shows that with the increase of the income coefficient of data sharing, the saddle point $G$ moves to point $(0,0)$, and the system evolves toward $(1,1)$; the probability of an enterprise selecting "participation strategy" increases, and both sides of game tend to participate collaborative innovation in supply chain at the same time. The bigger is the data sharing profit coefficient, the stronger is the capacity that the shared information generates income; therefore, the increase of the data sharing profit coefficient makes an enterprise gain more income and urges an enterprise to participate collaborative innovation in supply chain.

According to $\left(\partial^{2} S / \partial \alpha_{A}^{2}\right)=\left(2 P_{1}^{2} C_{0} / 4\left(R_{1}^{A}-(1 / 2)(1-\right.\right.$ $\left.\left.\left.\varepsilon_{A B}\right) C_{0}+\delta_{A}\left(R_{2}^{A}-C_{1}^{A}\right)+\left(\alpha_{A}-\beta_{A}-\gamma_{A}\right) P_{A}-R_{3}^{A}+C_{0}\right)^{3}\right)>$ 0 , similarly, $\left(\partial^{2} S / \partial \alpha_{B}^{2}\right)>0$, it will be found that with the increase of the income coefficient of data sharing, the velocity of an enterprise selecting the final strategy becomes higher and higher. The bigger the data sharing profit coefficient is, the more collaborative innovation income an enterprise gains, and therefore, the time of making decision becomes less, that is, the velocity becomes higher and higher.

Statement 2. The increase of cost coefficient of data sharing makes the probability of an enterprise selecting to participate collaborative innovation in supply chain decrease, and the velocity of approaching to the decision direction becomes higher and higher.

Proof. According to $\left(\partial S / \partial \beta_{A}\right)=\left(P_{1} C_{0} / 4\left(R_{1}^{A}-(1 / 2)(1-\right.\right.$ $\left.\left.\left.\varepsilon_{A B}\right) C_{0}+\delta_{A}\left(R_{2}^{A}-C_{1}^{A}\right)+\left(\alpha_{A}-\beta_{A}-\gamma_{A}\right) P_{A}-R_{3}^{A}+C_{0}\right)^{2}\right)>$
0, similarly, $\left(\partial S / \partial \beta_{B}\right)>0$, it will be found that related to $\beta_{i}, S$ appears monotone progressive increase. It shows that with the increase of the cost coefficient of information sharing, the saddle point $G$ moves to point $(1,1)$, and the system evolves toward $(0,0)$; the probability of an enterprise selects "no participation strategy" increases, and both sides of game approach to not participating collaborative innovation in supply chain. The higher is the cost of information sharing, the lower is the desire of an enterprise participating collaborative innovation in supply chain, and if the cost of data sharing of an enterprise is too high, the enterprise will select directly not to participate collaborative innovation in supply chain; therefore, the cost of data sharing hinders the decision of an enterprise participating collaborative innovation in supply chain.

According to $\left(\partial^{2} S / \partial \beta_{A}^{2}\right)=\left(P_{1}^{2} C_{0} / 2\left(R_{1}^{A}-(1 / 2)\left(1-\varepsilon_{A B}\right)\right.\right.$ $\left.\left.C_{0}+\delta_{A} \quad\left(R_{2}^{A}-C_{1}^{A}\right)+\left(\alpha_{A}-\beta_{A}-\gamma_{A}\right) P_{A}-R_{3}^{A}+C_{0}\right)^{3}\right)>0$, similarly, $\left(\partial^{2} S / \partial \beta_{B}^{2}\right)>0$, it will be found that with the increase of the cost coefficient of data sharing, the velocity of an enterprise selecting the final strategy becomes higher and higher. The bigger the data sharing cost coefficient is, the more the cost an enterprise must pay; in order to reduce cost investment, the time of making decision should be reduced, that is to say, the velocity becomes higher and higher.

Statement 3. The increase of security risk coefficient makes the probability of an enterprise selecting to participate collaborative innovation in supply chain decrease, and the velocity of approaching to the decision direction becomes higher and higher.

Proof. According to $\left(\partial S / \partial \gamma_{A}\right)=\left(P_{1} C_{0} / 4\left(R_{1}^{A}-(1 / 2)(1-\right.\right.$ $\left.\left.\left.\varepsilon_{A B}\right) C_{0}+\delta_{A}\left(R_{2}^{A}-C_{1}^{A}\right)+\left(\alpha_{A}-\beta_{A}-\gamma_{A}\right) P_{A}-R_{3}^{A}+C_{0}\right)^{2}\right)$ $>0$, similarly, $\left(\partial S / \partial \gamma_{B}\right)>0$, it will be found that related to $\gamma_{i}$, $S$ appears monotone progressive increase. It shows that with the increase of the security risk coefficient, the saddle point $G$ moves to point $(1,1)$, and the system evolves toward $(0,0)$; the probability of an enterprise selects "no participation strategy" increases, and both sides of game approach to not to participate collaborative innovation in supply chain. In the process of information sharing, the security risk brings the risk of information leakage to enterprises; therefore, in face of risk an enterprise always shows an evasive state.

According to $\left(\partial^{2} S / \partial \gamma_{A}^{2}\right)=\left(2 P_{1}^{2} C_{0} / 4\left(R_{1}^{A}-(1 / 2)(1-\right.\right.$ $\left.\left.\left.\varepsilon_{A B}\right) \quad C_{0}+\delta_{A}\left(R_{2}^{A}-C_{1}^{A}\right)+\left(\alpha_{A}-\beta_{A}-\gamma_{A}\right) P_{A}-R_{3}^{A}+C_{0}\right)^{3}\right)$ $>0$, similarly, $\left(\partial^{2} S / \partial \gamma_{B}^{2}\right)>0$, it will be found that with the increase of the security risk coefficient, the velocity of an enterprise selecting the final strategy becomes higher and higher. The bigger the security risk coefficient is, the greater the risk an enterprise faces up to, and on this condition, the enterprise will select not to participate more rapidly and clearly.

Statement 4. The increase of resource integration coefficient makes the probability of an enterprise selecting to participate collaborative innovation in supply chain increase, and the velocity of approaching to the decision direction becomes higher and higher. 
Proof. According to $\left(\partial S / \partial \delta_{A}\right)=\left(-\left(R_{3}^{A}-C_{1}\right) C_{0} / 4\left(R_{1}^{A}\right.\right.$ $-(1 / 2)\left(1-\varepsilon_{A B}\right) C_{0}+\delta_{A}\left(R_{2}^{A}-C_{1}^{A}\right)+\left(\alpha_{A}-\beta_{A}-\gamma_{A}\right) P_{A}-$ $\left.\left.R_{3}^{A}+C_{0}\right)^{2}\right)<0$, similarly, $\left(\partial S / \partial \delta_{B}\right)<0$, it will be found that related to $\delta_{i}, S$ appears monotone progressive decrease. It shows that with the increase of the resource integration coefficient, the saddle point $G$ moves to point $(0,0)$, and the system evolves toward $(1,1)$; the probability of an enterprise selects "participation strategy" increases, and both sides of game tend to participate the cooperation of collaborative innovation in supply chain. The capacity of resource integration includes the capacity for an enterprise to integrate with the logistics resource and customer resource in supply chain and the capacity of supplier's management. Enterprises reduce operation cost and improve logistics efficiency through standardization construction and centralized purchase mode. Therefore, the improvement of the capacity of source integration can make enterprises approach to participate in supply chain collaborative innovation.

According to $\left(\partial^{2} S / \partial \delta_{A}^{2}\right)=\left(2\left(R_{3}^{A}-C_{1}\right)^{2} C_{0} / 4\left(R_{1}^{A}-\right.\right.$ $(1 / 2) \quad\left(1-\varepsilon_{A B}\right) C_{0}+\delta_{A}\left(R_{2}^{A}-C_{1}^{A}\right)+\left(\alpha_{A}-\beta_{A}-\gamma_{A}\right) P_{A}-$ $\left.\left.R_{3}^{A}+C_{0}\right)^{3}\right)>0$, similarly, $\left(\partial^{2} S / \partial \delta_{B}^{2}\right)>0$, it will be found that with the increase of the source integration coefficient, the velocity of an enterprise selecting the final strategy becomes higher and higher. The bigger the source integration coefficient is, the more the income an enterprise gains in the process of source integration; therefore, the enterprise will select participating cooperation quickly.

Statement 5. The increase of trustworthiness makes the probability of an enterprise selecting to participate collaborative innovation in supply chain increase, and the velocity of approaching to the decision direction becomes higher and higher.

Proof. According to $\left(\partial S / \partial \varepsilon_{A B}\right)=\left(\left(-(1 / 2) C_{0}^{2}\right) / 4\left(R_{1}^{A}-(1 / 2)\right.\right.$ $\left(1-\varepsilon_{A B}\right) \quad C_{0}+\delta_{A}\left(R_{2}^{A}-C_{1}^{A}\right)+\left(\alpha_{A}-\beta_{A}-\gamma_{A}\right) P_{A}-R_{3}^{A}+$ $\left.\left.C_{0}\right)^{2}\right)<0$, it will be found that $S$ appears monotone progressive decrease related to $\varepsilon_{A B}$. It shows that with the increase of the trustworthiness, the saddle point $G$ moves to point $(0,0)$, and the system evolves toward $(1,1)$; the probability of enterprises selecting "participation strategy" increases, and both sides of game approach to participate the cooperation of collaborative innovation in supply chain. The higher the trustworthiness is, the less the cost an enterprise pays in supplier management, and the higher is the desire to share information with each other, correspondingly, the communication cost is decreased; what is more, in order to overcome the obstacle of information communication system, an enterprise may invest again to reform its inner information system, and the effect of trustworthiness of one enterprise will win the trustworthiness from the other enterprise as well, as a result, more enterprises are absorbed in supply chain and the innovation within a greater extent is launched. Therefore, the enhancement of the trustworthiness among enterprises is beneficial to carrying on collaborative innovation in supply chain with high efficiency.

According to $\left(\partial^{2} S / \partial \varepsilon_{A B}^{2}\right)=\left((1 / 2) C_{0}^{3} / 4\left(R_{1}^{A}-(1 / 2)(1-\right.\right.$ $\left.\left.\left.\varepsilon_{A B}\right) \quad C_{0}+\delta_{A}\left(R_{2}^{A}-C_{1}^{A}\right)+\left(\alpha_{A}-\beta_{A}-\gamma_{A}\right) P_{A}-R_{3}^{A}+C_{0}\right)^{3}\right)$ $>0$, it will be found that with the increase of the trustworthiness, the velocity of an enterprise selecting the final strategy becomes higher and higher. The higher the trustworthiness is, the better the ability of cooperation among enterprises is, and communication becomes better and faster, as a result, enterprises gain more income, and therefore, enterprises will select to participate quickly.

Statement 6. The increase of free rider income makes the probability of an enterprise selecting to participate collaborative innovation in supply chain decrease, and the velocity of approaching to the decision direction becomes higher and higher.

Proof. According to $\left(\partial S / \partial R_{3}^{A}\right)=\left(C_{0} / 4\left(R_{1}^{A}-(1 / 2)(1-\right.\right.$ $\left.\left.\left.\varepsilon_{A B}\right) C_{0}+\delta_{A}\left(R_{2}^{A}-C_{1}^{A}\right)+\left(\alpha_{A}-\beta_{A}-\gamma_{A}\right) P_{A}-R_{3}^{A}+C_{0}\right)^{2}\right)$ $>0$, similarly, $\left(\partial S / \partial R_{3}^{B}\right)>0$, it will be found that $S$ appears monotone progressive increase related to $R_{3}$. It shows that with the increase of the trustworthiness, the saddle point $G$ moves to point $(1,1)$, and the system evolves toward $(0,0)$; the probability of enterprises selecting "participation strategy" decreases, and both sides of game approach to not to participate the cooperation of collaborative innovation in supply chain. Enterprises always start from maximizing profits. Therefore, when free rider income increases, enterprises will select free rider income that can be obtained without paying any cost and therefore will not participate in supply chain collaborative innovation.

According to $\left(\partial^{2} S / \partial R_{3}^{A^{2}}\right)=\left((1 / 2) C_{0}^{3} / 4\left(R_{1}^{A}-(1 / 2)(1-\right.\right.$ $\left.\left.\left.\varepsilon_{A B}\right) \quad C_{0}+\delta_{A}\left(R_{2}^{A}-C_{1}^{A}\right)+\left(\alpha_{A}-\beta_{A}-\gamma_{A}\right) P_{A}-R_{3}^{A}+C_{0}\right)^{3}\right)$ $>0$, similarly, $\left(\partial^{2} S / \partial R_{3}^{B^{2}}\right)>0$, it will be found that with the increase of the free rider income, the velocity of an enterprise selecting the final strategy becomes higher and higher; the higher the free rider income is, the more the income an enterprise obtains without any cost, and therefore, an enterprise will firmly select the "no participation" strategy and make decision in less time.

\section{Numerical Simulation}

Because there are several enterprises in the supply chain, and in every network of supply chain, there are core enterprises and common enterprises, and furthermore, the collaborative innovation among enterprises may take place between core enterprises and common enterprise as well as between common enterprises, in order to observe comprehensively the different game evolution among every sort of enterprise, we select one core enterprise and two common enterprises to conduct simulation. We assume enterprise $A$ is a core enterprise, enterprise $B$ and enterprise $C$ are common enterprises and select numbers for them, considered that the capacity of the core enterprise is better than the common enterprise, we let the parameter value corresponding to enterprise $A$ is bigger than those corresponding to enterprise $B$ and enterprise $C$; the parameter values of common enterprises $B$ and $C$ are approximate, and we let the parameter value of enterprise $B$ is slightly bigger than that of enterprise $C$. Then we pair enterprise $A$ with enterprise $B$ and pair enterprise $B$ with enterprise $C$ to conduct simulation game, in order to verify the correctness 
TABLE 3: Simulation parameter valuation.

\begin{tabular}{ccccccccccccc}
\hline$i$ & $R_{0}^{i}$ & $R_{1}^{i}$ & $R_{2}^{i}$ & $R_{3}^{i}$ & $C_{1}^{i}$ & $C_{0}$ & $P_{i}$ & $\alpha_{i}$ & $\beta_{i}$ & $\gamma_{i}$ & $\delta_{i}$ & $\varepsilon_{i j}$ \\
\hline$A$ & 6 & 5 & 12 & 4 & 2 & 2 & 20 & 0.8 & 0.4 & 0.2 & 0.6 \\
$B$ & 5 & 3 & 6 & 3 & 1 & 2 & 10 & 0.4 & 0.2 & 0.1 & 0.4 & $\varepsilon_{A B}=\varepsilon_{C B}=0.4$ \\
$C$ & 4 & 2.5 & 4.5 & 2 & 0.5 & 2 & 10 & 0.3 & 0.1 & 0.1 & 0.2 & \\
\hline
\end{tabular}

of statements and analyze if the participation of the core enterprises has different influence on collaborative innovation in supply chain. Simulation parameter valuation is shown in Table 3.

Substituting the number into the replicated dynamic equation (12), we obtain the replicated dynamic equation of game between enterprise $A$ and enterprise $B$ :

$$
\begin{aligned}
& \frac{\mathrm{d} x}{\mathrm{~d} t}=x(1-x)(12.4 y-1), \\
& \frac{\mathrm{d} y}{\mathrm{~d} t}=y(1-y)(4.4 x-1) .
\end{aligned}
$$

The replicated dynamic equation of game between enterprise $B$ and enterprise $C$ :

$$
\begin{aligned}
& \frac{\mathrm{d} x}{\mathrm{~d} t}=x(1-x)(3.7 y-1) \\
& \frac{\mathrm{d} y}{\mathrm{~d} t}=y(1-y)(4.4 x-1) .
\end{aligned}
$$

5.1. The Influence of the Income Coefficient $\alpha_{i}$ on the Results of Both Game Sides Evolution. Under the condition that the other factors will not be changed, we analyze the influence of the change in simulation $\alpha_{i}$ on the enterprises $A, B$, and $C$. When $\alpha_{i}$ takes the values of $0.2,0.4,0.6$, and 0.8 , we get the results shown in Figure 6-9, and Statement 1 gets verified.

From Figures 6 and 7, it can be found that when core enterprises and common enterprises conduct collaborative innovation, no matter what value $\alpha_{i}$ takes, enterprise $B$ will select "participation strategy." When $\alpha_{A} \leq 0.2$, the core enterprise $A$ will select "no participation strategy," and only when the information coefficient is relatively big, it will select "participation strategy." The appearance of this threshold value tallies with the actual situation. The core enterprise always has ambitious aim and undertakes a lot of work such as construction of digital platform, which demand a high investment. As for the fixed cost, if the predicted data sharing income is relatively low, enterprises will not select participating collaborative innovation in supply chain, and if the predicted data sharing income increased, they will naturally select "participation strategy." The common characteristic of both enterprises $A$ and $B$ is that with the progressive increase of data sharing profit coefficient, the velocity of the probability of "participation strategy" approaching 1 becomes higher and higher, which indicates that enterprises tend to select to participate supply innovation comparatively.

From Figures 8 and 9, it can be found that when the two enterprises $A$ and $B$ participate collaborative innovation,

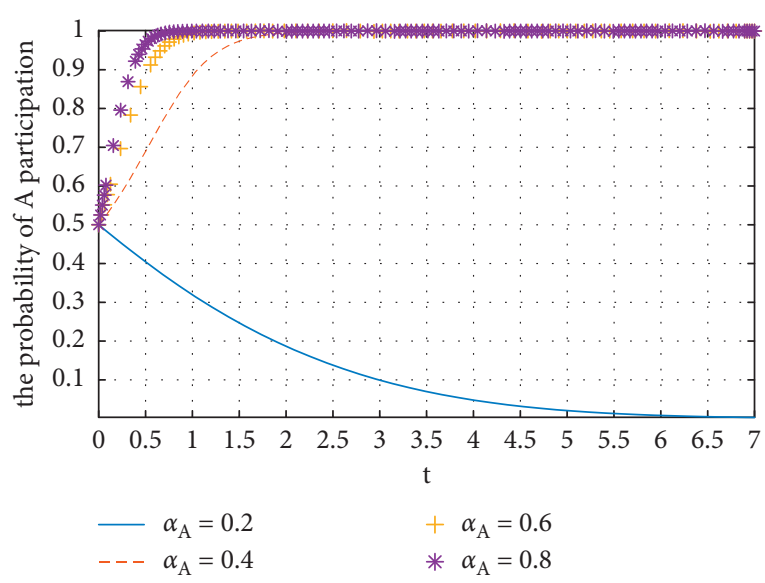

Figure 6: Influence of $\alpha_{A}$ on the core enterprise $A$.

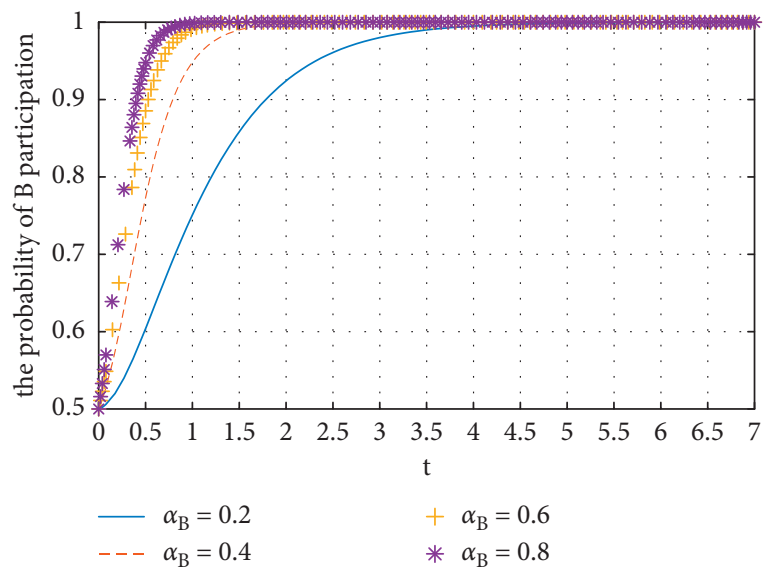

Figure 7: Influence of $\alpha_{B}$ on the common enterprise $B$.

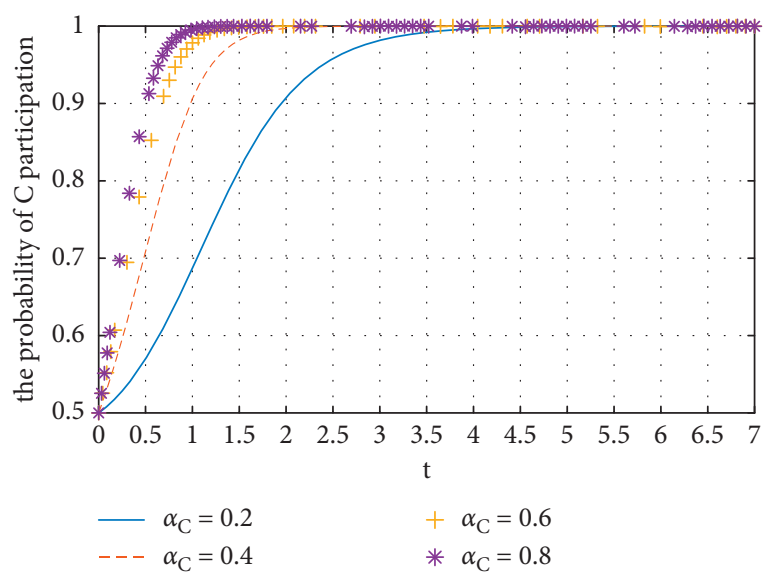

Figure 8: Influence of $\alpha_{C}$ on the common enterprise $C$. 


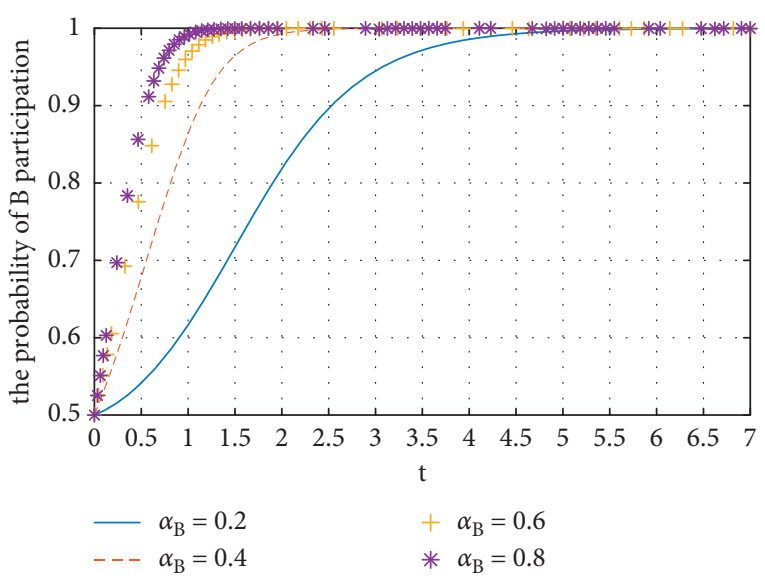

FIgURE 9: Influence of $\alpha_{B}$ on the common enterprise $B$.

both of them make a completely similar selection that approaches to "participation strategy." With the increase of the income coefficient of information sharing, the velocity of the probability of "participation strategy" approaching 1 becomes higher and higher. As for the velocity of the probability of "participation strategy" approaching 1, enterprise $C$ is faster than enterprise $B$, maybe it is because that the base of enterprise $C$ is slightly worse compared with enterprise $B$ and, in the aspects of digital technology and information technology, it has not much advantage in itself and it selects cooperation quickly in order to promote its growth and increase of income.

Comparing the displays of enterprise $B$ under the two conditions, no matter if there are core enterprises, it will select participating collaborative innovation in supply chain. When there are core enterprises, the velocity of the probability of "participation strategy" approaching 1 is higher than that in the condition without core enterprises. Maybe it is because that the core enterprise whose capacity of digitization technology is strong in itself, possesses more information, and can lead the cooperative enterprises to turn the advantage of data sharing into income so as to promote collaborative innovation in supply chain, and the desire of common enterprises to select "participation strategy" becomes more obvious. Yet, when both sides are common enterprises, their information quantity and information capacity in themselves are poor, and the income produced in data sharing is less, and therefore, the enterprises may select "participation strategy" slowly.

5.2. The Influence of Cost Coefficient $\beta_{i}$ on the Results of Both Game Sides Evolution. Under the condition that the other factors will not be changed, the influence of the change in simulation $\beta_{i}$ on the enterprises $A, B$, and $C$ is analyzed. When $\beta_{i}$ takes the values of $0.2,0.4,0.6$, and 0.8 , the evolution results shown in Figures 10-13 are obtained, and the numerical simulation verifies Statement 2; also, it has been found, when the enterprises $B$ and $C$ select the strategy, there is a threshold value of $\beta_{i}$.

From Figures 10 and 11, it can be found that when enterprise $A$ and enterprise $B$ play game concerning

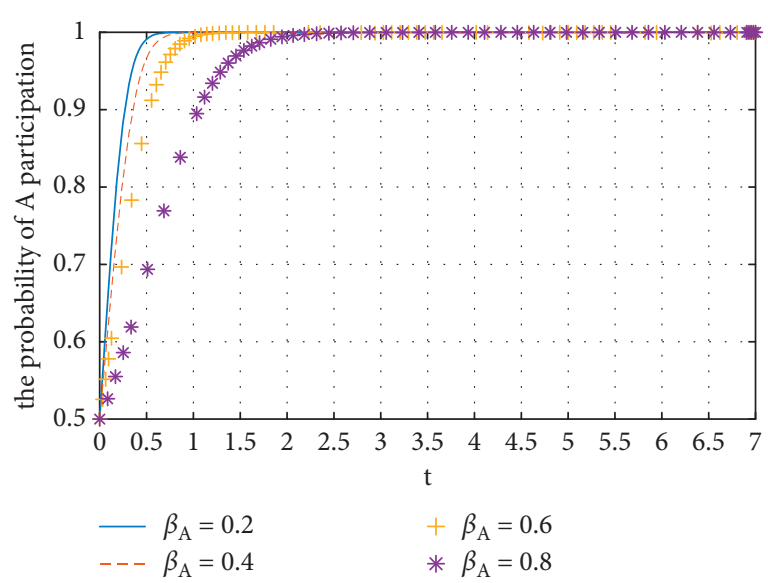

Figure 10: Influence of $\beta_{A}$ on the core enterprise $A$.

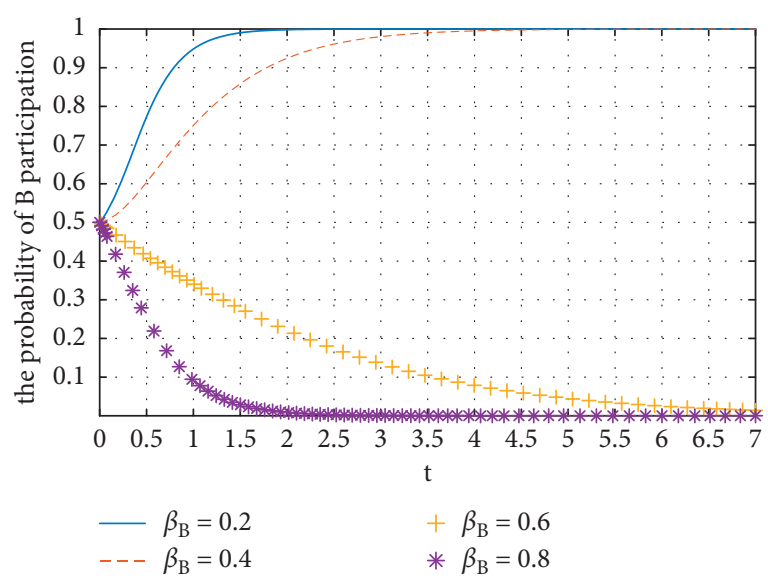

FIGURE 11: Influence of $\beta_{B}$ on the common enterprise $B$.

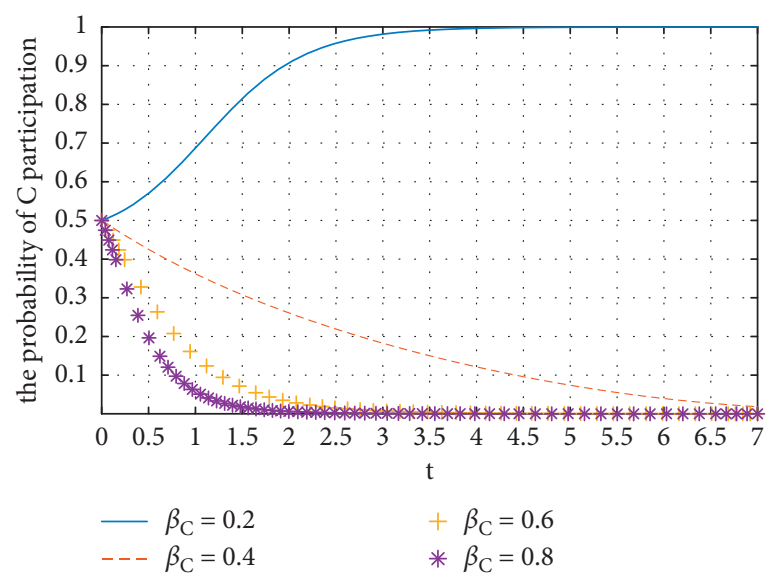

Figure 12: Influence of $\beta_{C}$ on the common enterprise $C$.

collaborative innovation in supply chain, against different cost coefficients of information sharing, the core enterprise $A$ will select participating collaborative innovation in supply chain, while the common enterprise $B$ will weigh the value of cost coefficient. When the cost coefficient is relatively big, the common enterprises will select "participation strategy," 


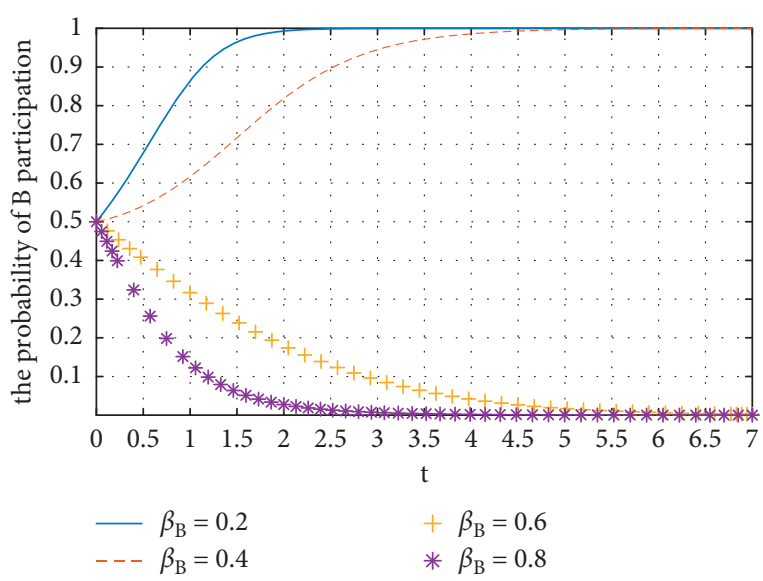

FIgURE 13: Influence of $\beta_{B}$ on the common enterprise $B$.

and with the increase of the cost coefficient of information sharing, the velocity of enterprises approaching selection of "no participation strategy" becomes higher and higher. When the cost of data sharing is low, the common enterprises will select to participate collaborative innovation in supply chain, and with the decrease of the cost coefficient of information sharing, the velocity of enterprises approaching selection of "participation strategy" becomes higher and higher. This is entirely consistent with the practice in which the core enterprises have great confidence in the future income; meanwhile, the sensitivity for cost of the common enterprise is higher than that of the core enterprise.

From Figures 12 and 13, it can be found that when the two common enterprises $B$ and $C$ play the game, for the decision of enterprise, there is a threshold value; when $\beta_{i}$ is small, enterprises will select "participation strategy," and with the increase of $\beta_{i}$, all enterprises will select "no participation strategy," between the enterprises the threshold value of enterprise $C$ is less than that of enterprise $B$. By analyzing the reason, we know: the cost sensitivity of the two enterprises is high, and the cost affordability for enterprise $C$ is poorer than that for enterprise $B$, so the threshold value, which influences decision, becomes low and the velocity of making decision becomes high, so only if it is thought that the income of data sharing can offset the paid cost, the two enterprises will select "participation strategy."

Comparing Figures 11 and 13, we can find that for enterprise $\mathrm{B}$ the threshold value and the tendency of selection have little change, but when playing the game with a core enterprise, it will make decision more rapidly. It indicates that for the common enterprises selecting "participation strategy," the cost of data sharing is a very big threshold and the amount of cost directly influences the selecting direction; in addition, there is a big gap between the common enterprises and the core enterprise, the sharp contrast makes enterprise B to do comparison and resolution more easily, and therefore, it will make decision more rapidly.

5.3. The Influence of Security Risk Coefficient $\gamma_{i}$ on the Results of Both Game Sides Evolution. Under the condition that the other factors will not be changed, the influence of the change in simulation $\gamma_{i}$ on the enterprises $A, B$, and $C$ selecting strategy is analyzed. When $\gamma_{i}$ takes the values of $0.2,0.4,0.6$, and 0.8 , the evolution results shown in Figures 14-17 are obtained, and the results of numerical simulation verify Statement 3; also, it has been found that in every graph, the coefficient $\gamma_{i}$ has a threshold value and in the enterprises the difference of threshold is great.

From Figures 14 and 15, it can be found that when enterprise $A$ and enterprise $B$ play game, and when the security risk coefficient is relatively big, both of them will select "no participation strategy," and with the decrease of the security risk coefficient, enterprises tend to select "participation strategy," and in addition, the threshold value of enterprise $A$ (between 0.6 and 0.8 ) is bigger than that of enterprise $B$ (between 0.4 and 0.6 ). Under the background of digitization, for the data security question leading various risks, it will hinder enterprises from selecting to participate collaboration innovation in supply chain, and only when the security risk coefficient is not big, the enterprises can select "participation strategy." The threshold value of the core enterprise is bigger than that of the common enterprises; maybe it is because that the risk-bearing capacity of the core enterprise is stronger.

From Figures 16 and 17, it can be found that the game between enterprise $B$ and enterprise $C$ is similar to the game between enterprise $A$ and enterprise $B$. Furthermore, comparing Figures 15 and 17, it can be found that the presence of core enterprise has little influence on the decision of the common enterprises, and they make decision based on their own actual situations; after all, their own risk must be borne by themselves. But when there are core enterprises, the common enterprises will make decision more rapidly. It indicates the promoting and leading effect of the core enterprises on collaborative innovation in supply chain, and the common enterprises clearly know how the gap between the two sides is, so they will make decision more rapidly.

\subsection{The Influence of Resource Integrative Capacity Coefficient} $\delta_{i}$ on the Results of Both Game Sides Evolution. Under the condition that the other factors will not be changed, the influence of the change in simulation $\delta_{i}$ on the enterprises $A$, $B$, and $C$ selecting strategy is analyzed. When $\delta_{i}$ takes the values of $0.2,0.4,0.6$, and 0.8 , the evolution results shown in Figures 18-21 are obtained, and the results of numerical simulation verify Statement 4.

From Figures 18 and 19, it can be found that when the enterprise $B$ plays game with the enterprise $A$, both of them will select "participation strategy," so with the increase of resource integration coefficient, the velocity of the probability of "participation strategy" approaching 1 becomes higher and higher, and the core enterprises are faster than the common enterprise. It indicates that both the two enterprises believe resource integration can bring forth income; besides, having strong capacity, the core enterprises make decision more rapidly. Furthermore, comparing Figures 19 and 20, it can be found that when there are core 


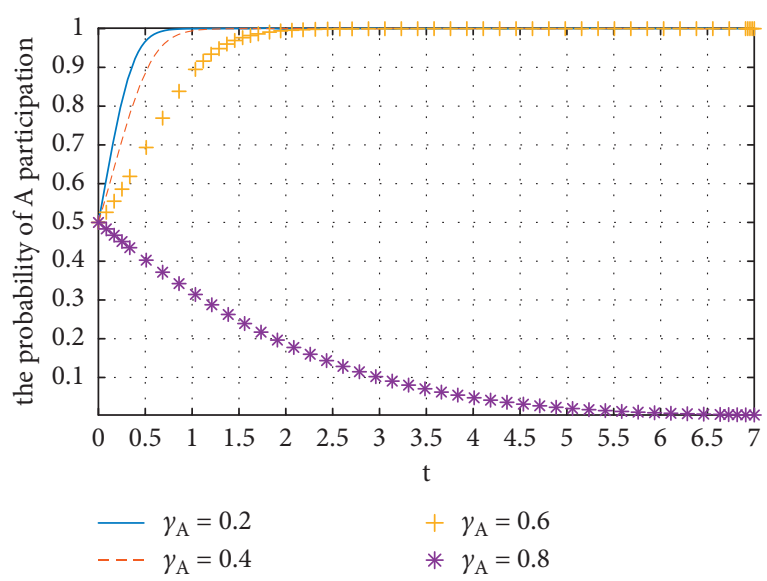

FIgURE 14: Influence of $\gamma_{A}$ on the core enterprise $A$.

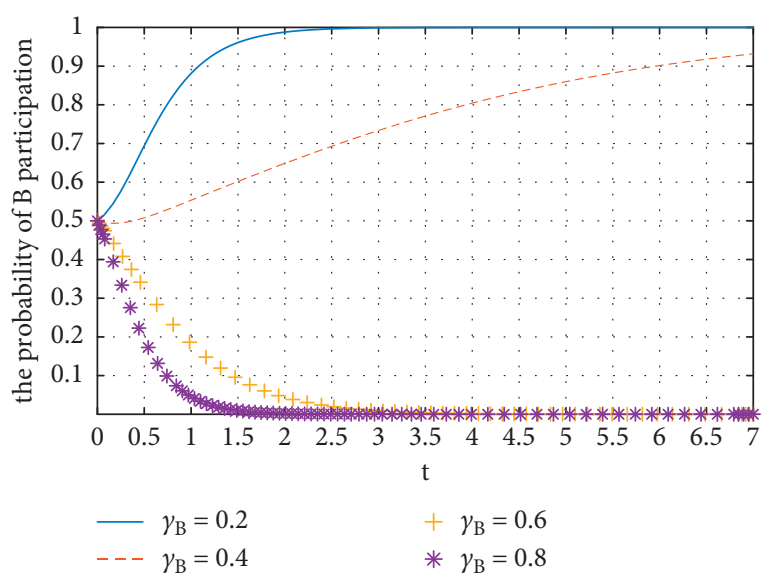

FIgURE 15: Influence of $\gamma_{B}$ on the common enterprise $B$.

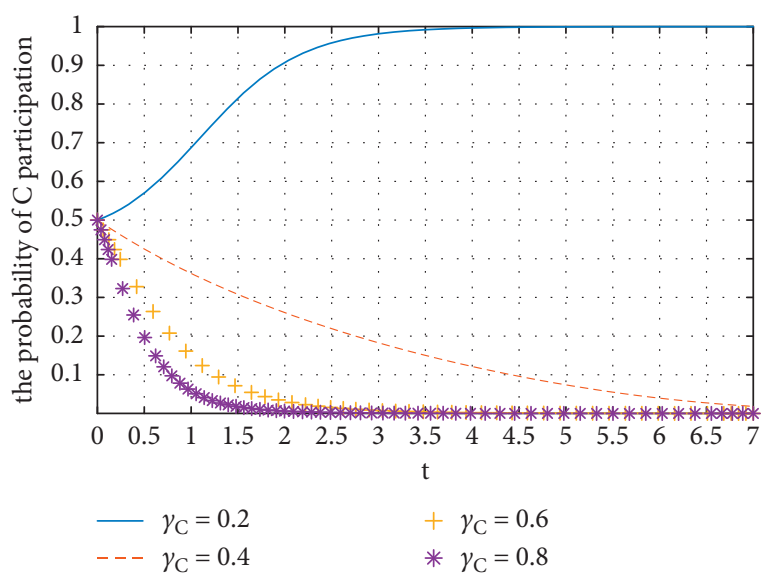

Figure 16: Influence of $\gamma_{C}$ on the common enterprise $C$.

enterprises, the velocity with which the probability of the common enterprises selecting "participation strategy" approaching 1 becomes higher and higher, and it indicates

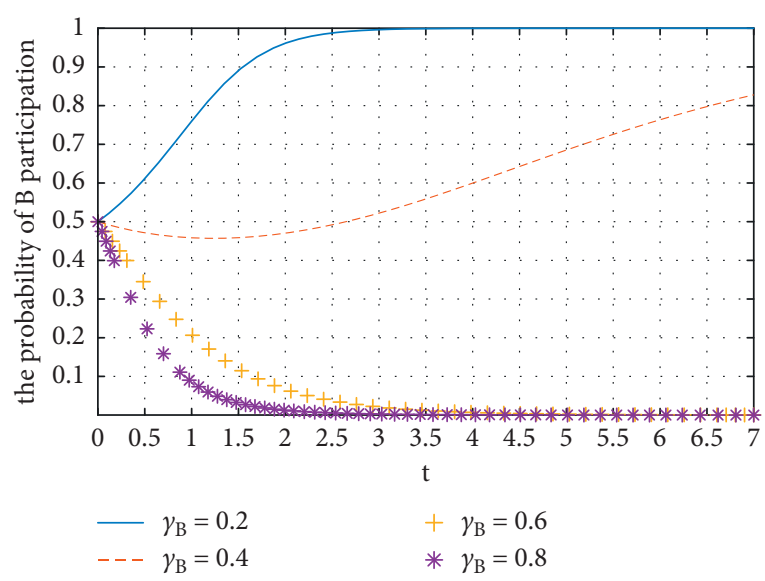

FIgURE 17: Influence of $\gamma_{B}$ on the common enterprise $B$.

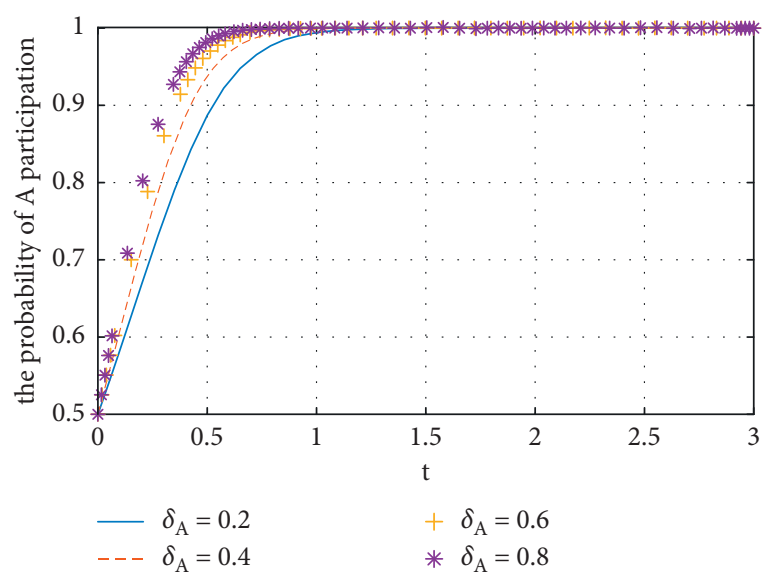

Figure 18: Influence of $\delta_{A}$ on the core enterprise $A$.

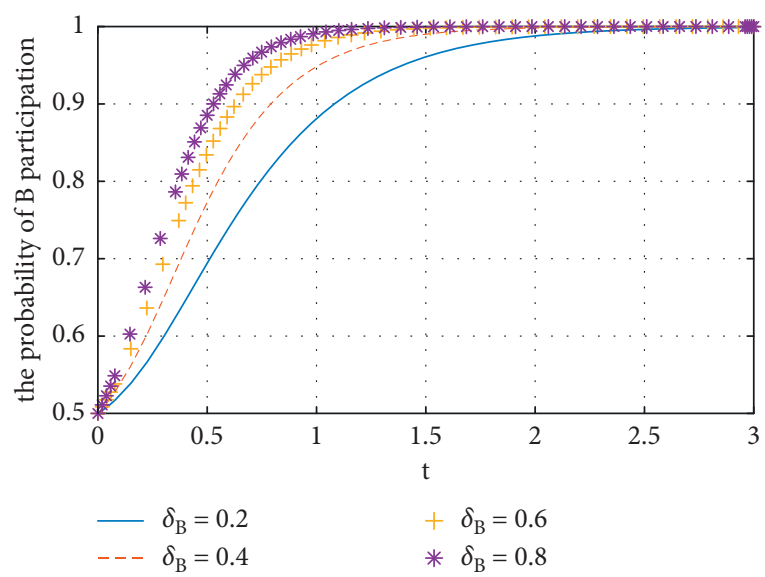

Figure 19: Influence of $\delta_{B}$ on the common enterprise $B$.

that, in the aspect of resource integration, the core enterprise really has an obvious leading effect on the common enterprises. 


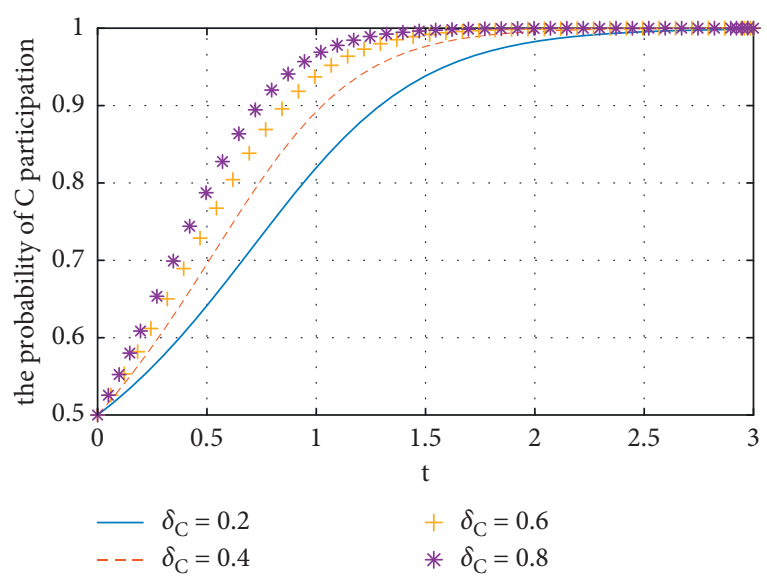

Figure 20: Influence of $\delta_{C}$ on the common enterprise $C$.

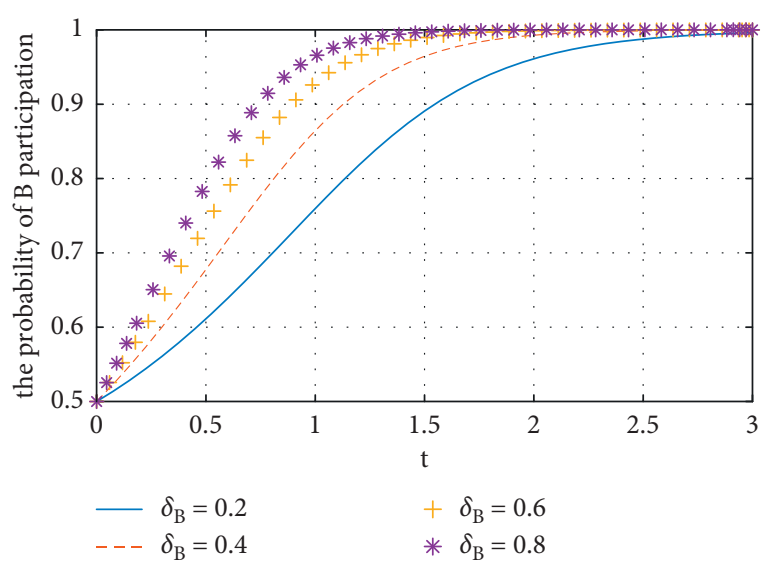

FIgURE 21: Influence of $\delta_{B}$ on the common enterprise $B$.

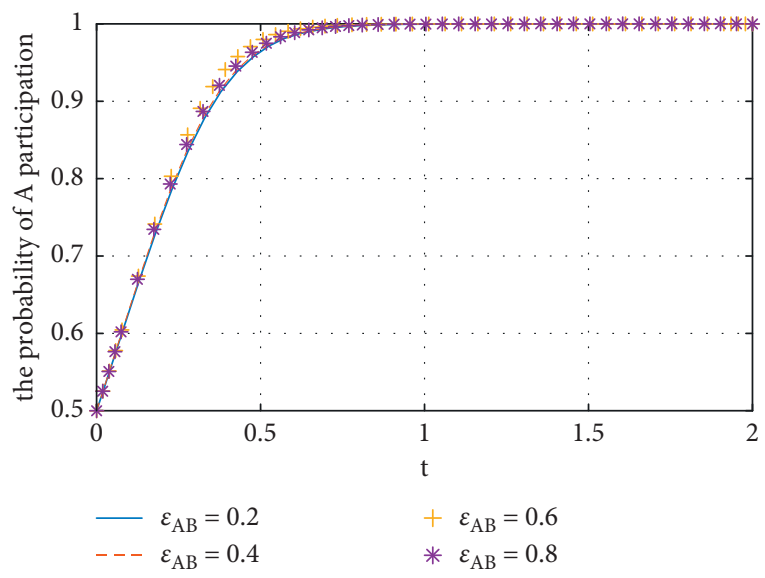

Figure 22: Influence of $\varepsilon_{A B}$ on the enterprise $A$.

5.5. The Influence of Trustworthiness Coefficient $\varepsilon$ on the Results of Both Game Sides Evolution. Under the condition that the other factors will not be changed, the influence of the change in simulation $\varepsilon$ on the enterprises $A, B$, and $C$

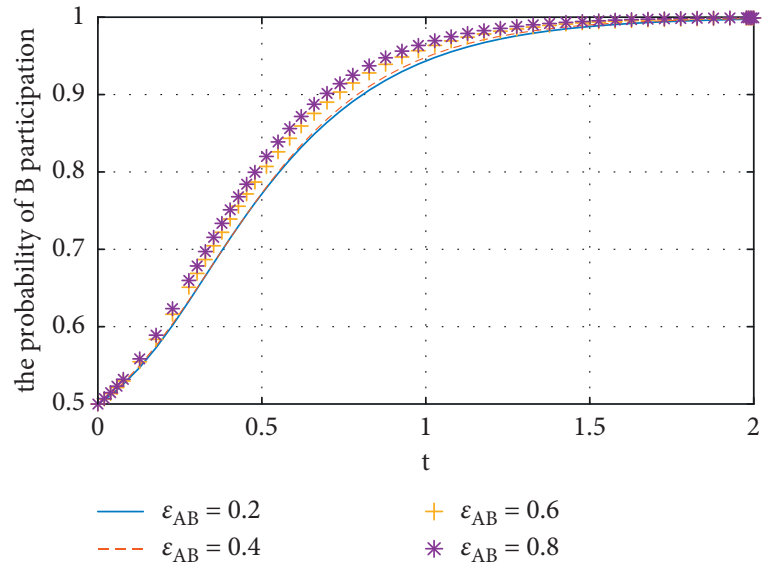

FIgURE 23: Influence of $\varepsilon_{A B}$ on the enterprise $B$.

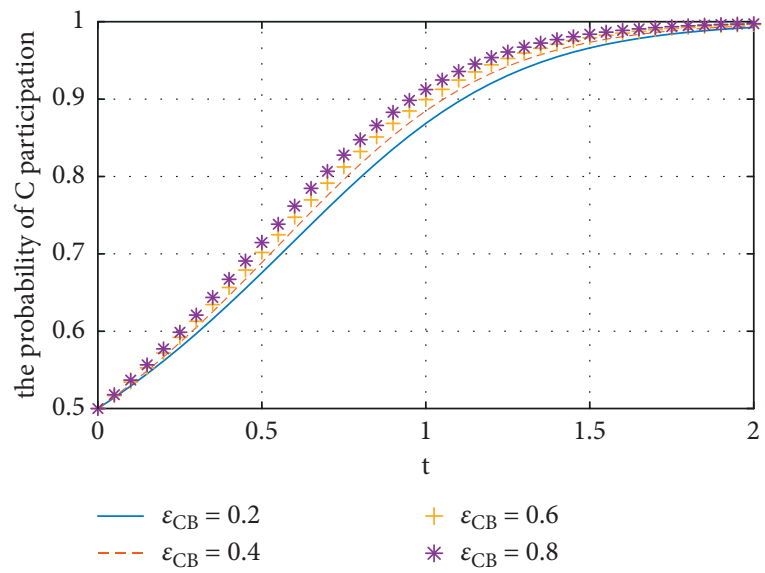

Figure 24: Influence of $\varepsilon_{C B}$ on the enterprise $C$.

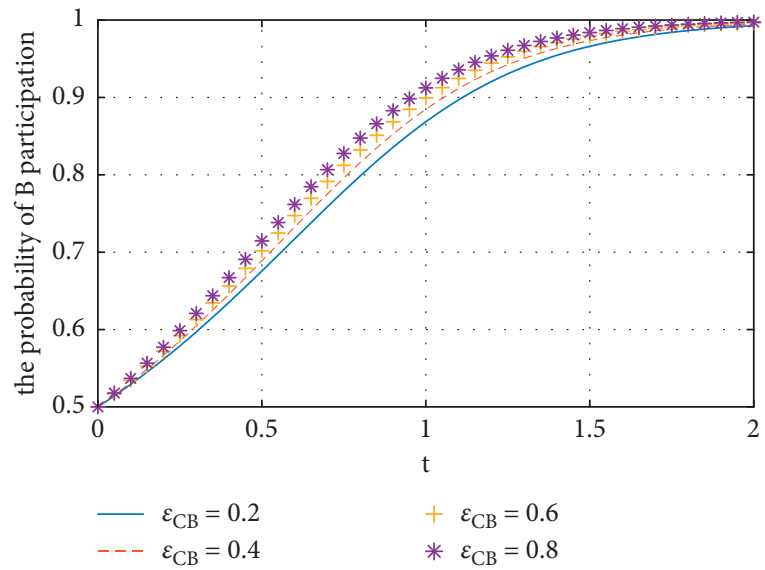

Figure 25: Influence of $\varepsilon_{C B}$ on enterprise $B$.

selecting strategy is analyzed. When $\varepsilon$ takes the values of 0.2 , $0.4,0.6$, and 0.8, the evolution results shown in Figures 22-25 are obtained, and the results of numerical simulation verify Statement 4 . 


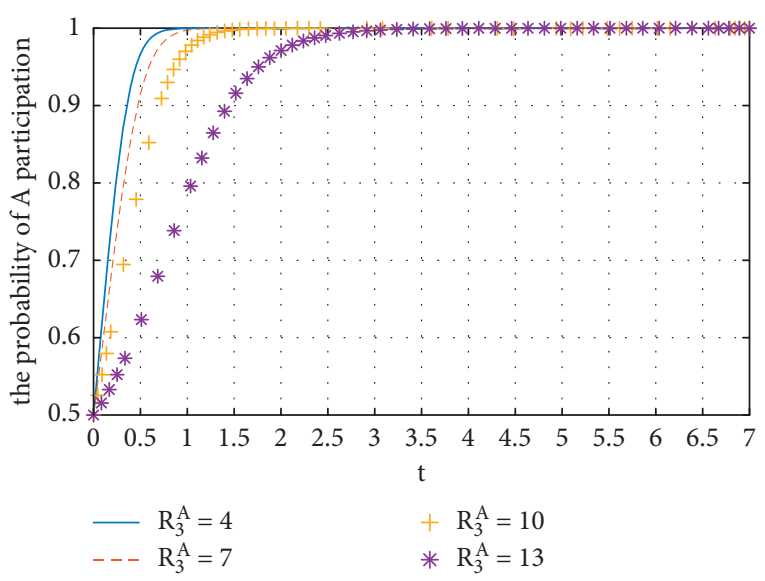

Figure 26: Influence of $R_{3}^{A}$ on the core enterprise $A$.

From Figures 22 and 23, it can be found that when the enterprise $A$ plays game with the enterprise $B$, the velocity with which the probability approaching 1 of enterprise A selecting "participation strategy" is significantly higher than that of enterprise $B$; additionally, comparing Figure 23 and 25 , it can be found that when the enterprise $B$ plays game with the core enterprise $A$, the velocity of the probability approaching 1 of its selecting "participation strategy" is higher than that when it plays game with the common enterprise $C$. In the same way, it indicates the leading effect of the core enterprises.

5.6. The Influence of Free Rider Income $R_{3}^{i}$ on the Results of Both Game Sides Evolution. Under the condition that the other factors will not be changed, the influence of the change in simulation $R_{3}^{i}$ on the enterprises $A, B$, and $C$ selecting strategy is analyzed. When $R_{3}^{i}$ takes the values of $4,7,10$, and 13, the evolution results shown in Figures 26-29 are obtained, and the results of numerical simulation verify Statement 6; also, it can be found that when enterprises $B$ and $C$ select the strategy, the $\gamma_{i}$ coefficient has threshold value between 4 and 7 .

From Figures 26 and 27, it can be found that when the enterprise $A$ plays game with the enterprise $B$, the core enterprise $A$ always selects "participation strategy," and with the increase of free rider income, the velocity of the probability approaching 1 of the core enterprise's participation will become slow, and it indicates its strong unwillingness to free rider behavior. With the increase of free rider income, the common enterprise $B$ will change its strategy, and only when free rider income is not more, it will select "participation strategy." Once free rider income reaches a certain degree, enterprises will select "no participation strategy"; after all, since an enterprise can obtain income without cost, attracted by income the common enterprises will select free rider without any hesitation.

From Figures 28 and 29, it can be found that when the two common enterprises $B$ and $C$ play game, as long as free rider income amounts to a value which exceeds the lowest threshold value, they will select "no participation strategy." In addition, the velocity with which the enterprise $C$

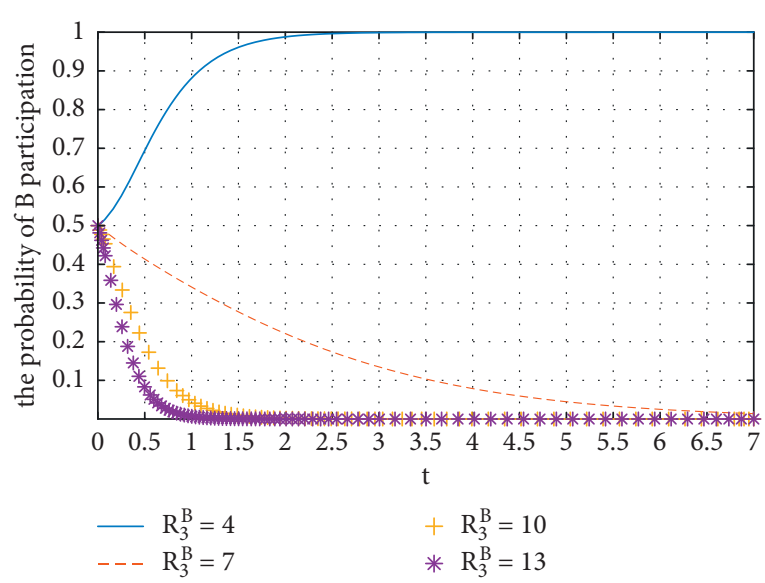

FIgURE 27: Influence of $R_{3}^{B}$ on the common enterprise $B$.

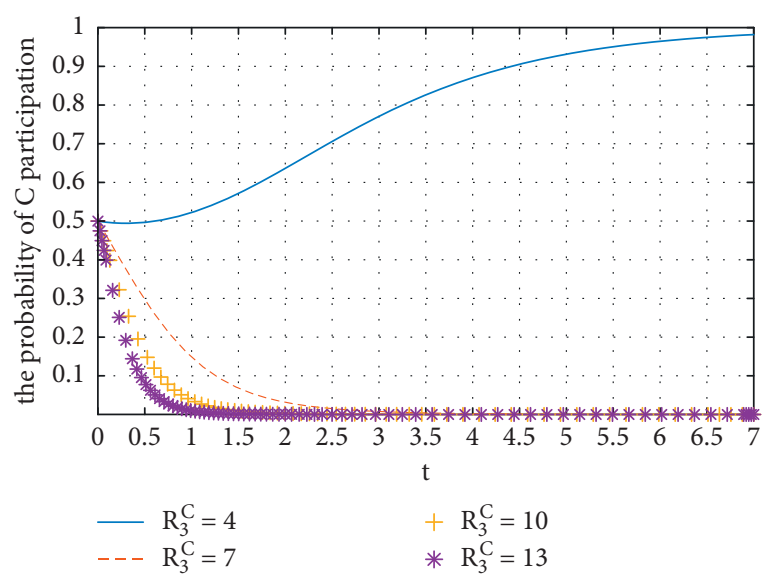

FIgURE 28: Influence of $R_{3}^{C}$ on the common enterprise $C$.

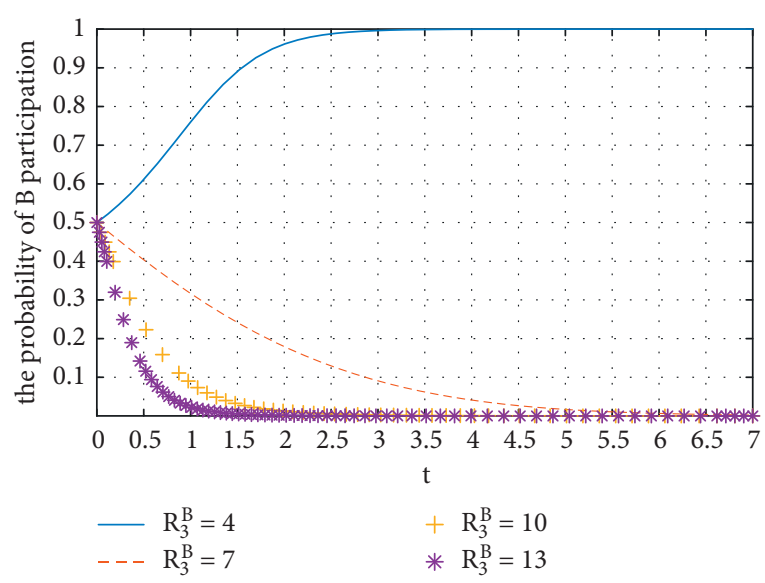

Figure 29: Influence of $R_{3}^{B}$ on the common enterprise $B$.

approaches the selection of "no participation strategy" is higher than that of the enterprise $B$, maybe it is because that in the several aspects of capacity the enterprise $C$ is slightly poor and has strong tendency toward free rider for obtaining income without paying cost. Furthermore, comparing 
Figures 27 and 29, it can be found that the presence of core enterprise has a little influence on the threshold value for the common enterprises making decision. The common enterprises balance collaborative innovation income against free rider income and will make decision finally. But when the core enterprises participate in the game, the enterprise $B$ will make decision more rapidly, likewise, it is because that the enterprise $B$ can realize quickly that the core enterprise $A$ has significant advantage in capacity over itself, so it will make decision soon.

\section{Conclusion and Enlightenment}

On the base of the analysis of the effect mechanism on collaborative innovation in supply chain, in consideration of the influence of both sides of game in correlative factors such as information sharing, resource integration, and trustworthiness on income and cost of an enterprise, this paper builds a dynamic evolution game model of enterprises participating collaborative innovation to solve the model and analyze the stability of game strategy of both sides as well as to prove the relative statements theoretically and verify them with the method of numerical simulation.

6.1. The Main Research Conclusion. The results of research are as follows:

(1) The increase of data sharing profit coefficient, resource integration coefficient, and trustworthiness coefficient increase the probability of enterprises participating collaborative innovation in supply chain, and the velocity of enterprises approaching the direction of decision becomes higher and higher.

(2) The increase of data sharing cost coefficient, security risk coefficient, and free rider income causes the decrease of the probability of enterprises participating collaborative innovation in supply chain, and the velocity of enterprises approaching the direction of decision becomes higher and higher.

(3) The numerical simulation shows that, for the probability the core enterprises or the common enterprises participating collaborative innovation in supply chain, the income coefficient of information sharing, the cost of information sharing, security risk coefficient, and free rider income have threshold values.

(4) The core enterprises participating the game can drive the common enterprises make decision more quickly.

6.2. The Main Enlightenments. The research in this paper brings the following enlightenments:

6.2.1. Attach great importance to digitization construction. Data sharing income and resource integration income are the cardinal driving forces. The digitization construction in enterprises has significant effect on the promotion of the degree of data sharing and the strength of resource integration. It is the foundation stone of enterprises to reinforce enterprises in comprehension of digitization innovation as well as to cultivate and improve digitization capacity of enterprise. Collaborative innovation in supply chain depends on the increase of the digitization level in every enterprise, and innovation in supply chain needs active participation and joint promotion.

6.2.2. Play the leading role of core enterprises. The core enterprises in supply chain have a great advantage in the aspects of technology, resource, and management capacity. While leading and encouraging all enterprises to participate collaborative innovation in supply chain, the government should pay attention to the leading effect from the core enterprises, especially the platform enterprises under the background of digitization, and find out the core enterprises to be spurred timely and then impel the core enterprises to lead collaborative innovation in supply chain.

6.2.3. Government gives subsidies for breaking out threshold values. In general, a threshold value is a critical value of the difference between the expected income and cost, which determines the direction enterprises making decision. As the government plays an important leading role in making industrial policies and promoting the development of collaborative innovation in supply chain, in the specific analysis of different industry, it should give some proper subsidies to the enterprises that have the potential for innovation but still hesitate for being perplexed with cost, so as to urge enterprises to breakout the boundary of threshold values and take the strategy of participating collaborative innovation in supply chain sooner, as a result, the efficiency of the whole network of supply chain will be increased finally.

6.2.4. Exert the effect of data encryption technology and protect achievement in innovation. The free rider behavior is disadvantageous to the trustworthiness construction and the long-term healthy development of supply chain. The data encryption technology in the construction of digitization platform should be utilized to the full, and in contract, the permissions of the resources such as information should rationally set in order to protect innovation patents and achievements.

6.3. Insufficient Research. The research of this paper has rather more theoretical value and practical significance; though, there are some deficiencies to be deeply researched, for instance, not verifying the related conclusions with actual data of enterprises and the lack of further analysis of the specific situation of the threshold value upon enterprises making decision and the leading effect exerted by the core enterprises. 


\section{Data Availability}

The data used to support the findings of this study are included within the article.

\section{Conflicts of Interest}

The authors declare that there are no conflicts of interests regarding the publication of this paper.

\section{Acknowledgments}

This work was supported by the National Natural Science Foundation of China (Grant no. 72001182), the Humanities and Social Science Fund of Ministry of Education of China (Grant nos. 18YJA630131 and 19YJC630159), and the FirstClass Discipline Construction Project of Business Administration of Shanxi University of Finance and Economics under the "1331" Project of Shanxi Province (Grant no. 83 [2021]).

\section{References}

[1] Y. Yoo, O. Henfridsson, and K. Lyytinen, "Research commentary-the new organizing logic of digital innovation: an agenda for information systems research," Information Systems Research, vol. 21, no. 4, pp. 724-735, 2010.

[2] S. Nambisan, K. Lyytinen, and K. Majchrzak, "Digital innovation management: reinventing innovation management research in a digital world," MIS Quarterly, vol. 41, no. 1, pp. 223-238, 2017.

[3] S. Wang and F. Liu, "Cooperative innovation in a supply chain with different market power structures," American Journal of Operations Research, vol. 6, no. 2, pp. 173-198, 2016.

[4] Y. X. Luo, "Exploration into China's agricultural products logistics development under the supply chain management," in Proceedings of the International Conference on Information Management, Innovation Management and Industrial Engineering IEEE, Shenzhen, China, November 2011.

[5] S. C. Li and P. Gao, "Study on the exploratory factors affecting the knowledge acquisition of manufacturing enterprises-supplier network perspective," Studies in Science of Science, vol. 28, no. 10, pp. 1540-1546, 2010.

[6] M. Cao and Q. Zhang, "Supply chain collaborative advantage: a firm's perspective," International Journal of Production Economics, vol. 128, no. 1, pp. 358-367, 2010.

[7] B. Mark, "Understanding the meaning of collaboration in the supply chain," Supply Chain Management, vol. 9, no. 1, pp. 30-42, 2004.

[8] J. Cao and X. Zhang, "Coordination strategy of green supply chain under the free market mechanism," Energy Procedia, vol. 36, pp. 1130-1137, 2013.

[9] C. L. Dong, "Discussion on collaborative innovation paths and strategies of circulation supply chain under the background of new retail," Coastal Enterprises and Technology, vol. 6, pp. 31-35, 2019.

[10] D. C. Freitas, L. G. Oliveira, and R. L. C. Alcantara, “A theoretical framework to adopt Collaborative initiatives in supply chains," Gestão \& Produção, vol. 26, no. 3, p. 4194, 2019.

[11] W. A. P. Dania, K. Xing, and Y. Amer, "Collaboration behavioral factors for sustainable agri-food supply chains: a systematic review," Journal Of Cleaner Production, vol. 10, p. 186, 2018.

[12] T. L. Huynh and H. P. Nguyen, "Measure of bullwhip effect in supply chains: the case of high order autoregressive demand process," European Journal of Operational Research, vol. 183, 2007.

[13] B. Z. Li, X. Wang, and Y. Su, "Research on the evolutionary game of collaborative innovation of supply chain enterprises among strategic emerging industries in my country," China Management Science, vol. 12, pp. 1-12, 2020.

[14] S. M. Lee, D. L. Olson, and S. Trimi, "Co-innovation: convergenomics, collaboration, and co-creation for organizational values," Management Decision, vol. 50, no. 5, pp. 817-831, 2012.

[15] I. M. B. Freitas, R. A. Marques, and E. Silva, "University-industry collaboration and innovation in emergent and mature industries in new industrialized countries," Research Policy, vol. 42, no. 2, pp. 443-453, 2013.

[16] J. Hulland, R. W. Michael, and D. A. Kersi, "The impact of capabilities and prior investments on online channel commitment and performance," Journal of Management Information Systems, vol. 23, no. 4, 2007.

[17] J. Olhager and D. I. Prajogo, "The impact of manufacturing and supply chain improvement initiatives: a survey comparing make-to-order and make-to-stock firms," Omega, vol. 40, no. 2, pp. 159-165, 2012.

[18] M. Fritsch and R. Lukas, "Who cooperates on R\&D?" Research Policy, vol. 30, no. 2, pp. 297-312, 2001.

[19] S. A. Chung and G. M. Kim, "Performance effects of partnership between manufacturers and suppliers for New product development: the supplier's standpoint," Research Policy, vol. 32, no. 4, pp. 587-603, 2003.

[20] K. N. S. Iyer, "Demand chain collaboration and operational performance: role of IT analytic capability and environmental uncertainty," Journal of Business \& Industrial Marketing, vol. 26, no. 1-2, pp. 81-91, 2011.

[21] J. H. Xiao, K. Xie, and Y. Wu, "Supply chain transformation from partner-oriented to consumer-oriented: a double case study of e-commerce enterprise supply chain," Management World, vol. 4, pp. 137-154, 2015.

[22] F. Svahn and F. Mathiassen, "Mastering the digital innovation challenge," MIT Sloan Management Review, vol. 58, no. 3, pp. 14-16, 2017.

[23] Y. Yoo, J. R. J. Boland, and K. Lyytinen, "Organizing for innovation in the digitized world," Organization Science, vol. 23, no. 5, pp. 1398-1408, 2012.

[24] M. Esmaeili, M. B. Aryanezhad, and P. Zeephongsekul, "A game theory approach in seller-buyer supply chain," European Journal of Operational Research, vol. 195, no. 2, pp. 442-448, 2009.

[25] S. Barari, G. Agarwal, and W. J. Zhang, "A decision framework for the analysis of green supply chain contracts: an evolutionary game approach," Expert Systems with Applications, vol. 39, no. 3, pp. 2965-2976, 2012.

[26] Q. H. Zhu and Y. J. Dou, "Evolutionary game model between governments and core enterprises in greening supply chains," Systems Engineering-Theory \& Practice Online, vol. 27, no. 12, pp. 85-89, 2007.

[27] Y. L. Wang, N. Yu, and N. E. Yao, "The mechanism and effect of digital economy empowering manufacturing quality change-based on the theory and empirical evidence of dual margin," China Circulation Economy, vol. 34, no. 12, pp. 60-71, 2020. 
[28] M. Raweewan and W. G. Ferrell, "Information sharing in supply chain collaboration," Computers \& Industrial Engineering, vol. 38, 2018.

[29] A. Jha, K. Fernandes, and Y. Xiong, "Effects of demand forecast and resource sharing on collaborative new product development in supply chain," International Journal of Production Economics, vol. 193, pp. 207-221, 2017.

[30] D. Jimenez-Jimenez, M. Martínez-Costa, and C. S. Rodriguez, "The mediating role of supply chain collaboration on the relationship between information technology and innovation," Journal of Knowledge Management, vol. 23, no. 4, 2018.

[31] T. C. Kuo, C. W. Hsu, and S. H. Huang, "Information sharing: a collaborative model for a green textile/clothing supply chain," International Journal of Computer Integrated Manufacturing, vol. 27, no. 3, 2013.

[32] C. Wang and Q. Hu, "Knowledge sharing in supply chain networks: effects of collaborative innovation activities and capability on innovation performance," Technovation, vol. 9495, 2017.

[33] M. Kim and S. Chai, "The impact of supplier innovativeness, information sharing and strategic sourcing on improving supply chain agility: global supply chain perspective," International Journal of Production Economics, vol. 187, pp. 42-52, 2017.

[34] P. Hurmelinna-Laukkanen, "Enabling collaborative innovation-knowledge protection for knowledge sharing," European Journal of Innovation Management, vol. 14, no. 3, pp. 303-321, 2011.

[35] Y. M. Wang and J. W. Bao, "Evolutionary game analysis of knowledge sharing behavior in cluster supply chain," Science and Technology Management Research, vol. 4, pp. 142-149, 2019.

[36] B. R. Zhang, "Research on supply chain synergy based on resource integration," Journal of Suzhou Education College, vol. 17, no. 5, 2014.

[37] S. F. Wang and X. Y. Wang, "Research on the integration mechanism and sharing paths of supply chain collaborative resources between enterprises," Social Science Front, vol. 3, 2020.

[38] K. Heimeriks and M. Schreiner, "Relational quality, alliance capability, and alliance performance: an integrated framework," Advances in Applied Business Strategy, vol. 12, 2010.

[39] L. Cassivi, P. Hadaya, and E. Lefebvre, "The role of collaboration on process, relational, and product innovations in a supply chain," International Journal of E-Collaboration, vol. 4, no. 4, pp. 11-32, 2008.

[40] C. Mattos and F. Laurindo, "Collaborative platforms for supply chain integration: trajectory, assimilation of platforms and results," Journal of Technology Management and Innovation, vol. 10, no. 2, pp. 80-92, 2015.

[41] Z. Q. Wang, B. F. Huo, and Y. N. Qi, "A resource-based view on enablers of supplier integration: evidence from China," Industrial Management \& Data Systems, vol. 116, 2016.

[42] D. M. Neutzling, A. Land, and S. Seuring, "Linking sustainability-oriented innovation to supply chain relationship integration," Journal of Cleaner Production, vol. 172, no. 3, pp. 3448-3458, 2017.

[43] I. Badraoui, V. Van Der, and G. A. J. Jack, "Horizontal logistics collaboration: an exploratory study in Morocco's agrifood supply chains," International Journal of Logistics, vol. 23, pp. 1-18, 2019.

[44] J. B. Barney and M. H. Hanson, "Trustworthiness as a source of competitive advantage," Long Range Planning, vol. 15, no. 1, pp. 175-190, 1994.
[45] Y. H. Chen, Z. G. Zhang, and L. Huang, "The mechanism and path of digital empowerment business model innovation for manufacturing enterprises," Chinese Journal of Management, vol. 18, no. 5, pp. 731-740, 2021.

[46] S. E. Fawcett, S. L. Jones, and A. M. Fawcett, "Supply chain trust: the catalyst for collaborative innovation," Business Horizons, vol. 55, no. 2, pp. 163-178, 2012.

[47] F. E. Zeng, T. Zheng, and Z. F. Zhan, "Research on the impact of communication types and inter-firm interaction environment on organizational performance from the perspective of contingency," Chinese Journal of Management, vol. 15, no. 10, pp. 1003-1010, 2018.

[48] H. Feng, L. Nie, and Y. L. Shi, "The interaction between supply chain governance mechanism and supply chain performance: based on the mediation effect of information sharing and the moderating effect of information technology level," Chinese Management Science, vol. 28, no. 2, pp. 104-114, 2020. 